\title{
How Cytochromes with Different Folds Control Heme Redox Potentials ${ }^{\dagger}$
}

\author{
Junjun Mao, Karin Hauser, and M. R. Gunner* \\ Physics Department J-419, City College of New York, 138th Street and Convent Avenue, New York, New York 10031
}

Received December 3, 2002; Revised Manuscript Received June 11, 2003

\begin{abstract}
The electrochemical midpoint potentials ( $E_{\mathrm{m}}$ 's) of 13 cytochromes, in globin $\left(c, c_{2}, c_{551}, c_{553}\right)$, four-helix bundle $\left(c^{\prime}, b_{562}\right), \alpha \beta$ roll $\left(\mathrm{b}_{5}\right)$, and $\beta$ sandwich $(f)$ motifs, with $E_{\mathrm{m}}$ 's spanning $450 \mathrm{mV}$ were calculated with multiconformation continuum electrostatics (MCCE). MCCE calculates changes in oxidation free energy when a heme-axial ligand complex is moved from water into protein. Calculated and experimental $E_{\mathrm{m}}$ 's are in good agreement for cytochromes with His-Met and bis-His ligated hemes, where microperoxidases provide reference $E_{\mathrm{m}}$ 's. In all cytochromes, $E_{\mathrm{m}}$ 's are raised by $130-260 \mathrm{mV}$ relative to solvated hemes by the loss of reaction field (solvation) energy. However, there is no correlation between $E_{\mathrm{m}}$ and heme surface exposure. Backbone amide dipoles in loops or helix termini near the axial ligands raise $E_{\mathrm{m}}$ 's, but amides in helix bundles contribute little. Heme propionates lower $E_{\mathrm{m}}$ 's. If the propionic acids are partially protonated in the reduced cytochrome, protons are released on heme oxidation, contributing to the $\mathrm{pH}$ dependence of the $E_{\mathrm{m}}$. In all cytochromes studied except $b_{5}$ 's and low potential globins, buried side chains raise $E_{\mathrm{m}}$ 's. MCCE samples ionizable group protonation states, heme redox states, and side chain rotamers simultaneously. Globins show the largest structural changes on heme oxidation and four-helix bundles the least. Given the calculated protein-induced $E_{\mathrm{m}}$ shift and measured cytochrome $E_{\mathrm{m}}$ the five-coordinate, His heme in $c^{\prime}$ is predicted to have a solution $E_{\mathrm{m}}$ between that of isolated bis-His and His-Met hemes, while the reference $E_{\mathrm{m}}$ for His-Ntr ligands in cytochrome $f$ should be near that of His-Met hemes.
\end{abstract}

Cytochromes are a diverse family of heme-containing proteins that are components of electron transfer chains $(1,2)$. There are soluble, extrinsic, and intrinsic membrane cytochromes. While they are usually all $\alpha$ (3), they are also found in $\alpha \beta$ and all $\beta$ folds. Cytochrome heme electrochemical midpoint potentials $\left(E_{\mathrm{m}}{ }^{\prime} \mathrm{s}\right)^{1}$ vary between -400 and +400

\footnotetext{
† Supported by the National Science Foundation MCB 0212696. K.H. acknowledges a Feodor Lynen Fellowship from the Alexander von Humboldt Foundation.

* To whom correspondence should be addressed. Telephone: 212650-5557. Fax: 212-650-6940. E-mail: gunner@sci.ccny.cuny.edu.

${ }^{1}$ Abbreviations: All free energy terms $\Delta G$ and electrochemical midpoints $\left(E_{\mathrm{m}}\right)$ refer to standard conditions at $\mathrm{pH} 7\left(\Delta G^{\circ \prime}\right.$ and $\left.\mathrm{E}^{\circ \prime}{ }_{\mathrm{m}}\right)$. $1.36 \mathrm{kcal} / \mathrm{mol}=58 \mathrm{meV}=1 \Delta \mathrm{p} K_{\mathrm{a}}$ unit $=$ the energy to change a $\mathrm{p} K_{\mathrm{a}}$ by $1 \mathrm{pH}$ unit at $25^{\circ} \mathrm{C}$.
}

$\mathrm{mV}$ (vs SHE) (4-6). This $800 \mathrm{mV} E_{\mathrm{m}}$ span represents an $18.8 \mathrm{kcal} / \mathrm{mol}$ change in free energy of heme ionization, equivalent to changing an active site residue $\mathrm{p} K_{\mathrm{a}}$ by 13.8 $\mathrm{pH}$ units. The range of cytochrome redox potentials results from differences in stabilization of the buried, cationic, oxidized heme by proteins in different motifs $(7,8)$.

Redox reactions of cofactors such as hemes, quinones (911) and iron-sulfur complexes $(12-15)$ have been studied by continuum electrostatics (16), free energy perturbation and microscopic LRA $(17,18)$, molecular dynamics $(19,20)$, quantum mechanical $(14,21)$, and $\mathrm{QM} / \mathrm{MM}(22)$ techniques. Each cofactor type and analysis method provides different insights into the role of the local ligand geometry (15), backbone dipoles $(12,13,23)$, side chains (14), and protein 
reorganization $(24,25)$ in modulating the reaction free energy. Studies which focus on electrostatic contributions use theoretical methodology analogous to that developed to study electrostatic perturbations of residue $\mathrm{p} K_{\mathrm{a}}$ 's $(26-33)$. These methods, which will be used here, assume residue $\mathrm{p} K_{\mathrm{a}}$ 's and $E_{\mathrm{m}}$ 's of heme-axial ligand complexes maintain the same intrinsic chemistry in solution and protein $(7,16$, 26, 34-39). Thus, the free energy difference between polar and ionized forms that determines the $\mathrm{p} K_{\mathrm{a}}$ or $E_{\mathrm{m}}$ is modified only by the different electrostatic interactions in the two environments.

Experimental (40-45) and theoretical $(20,46-52)$ studies have analyzed the sources of the large range of cytochrome $E_{\mathrm{m}}$ 's. Protein modulation of electrostatic interactions appears to be the most important $(6,8,17,23,34,36,37)$. Kassner recognized that the loss of reaction field (solvation) energy moving the heme from water to protein always destabilizes the charged, oxidized heme shifting the $E_{\mathrm{m}}$ to more positive values $(53,54)$. Warshel, using the atomic structures of cytochrome $c$ with the PDLD method, was able to make better estimates of the loss in reaction field energy and to study the importance of the propionic acids and protein residues $(7,17)$. Rogers and Moore solved the PoissonBoltzmann equation of continuum electrostatics (55) to estimate how the $\mathrm{pH}$-dependent ionization of the heme propionates would influence the $E_{\mathrm{m}}$ of cytochrome $c_{551}$ (56, 57). Continuum electrostatics has been used to analyze multiheme cytochrome $c_{3}(50,51,58)$ and Rhodopseudomonas viridis reaction centers (8), allowing comparison of several hemes in a single structure. The studies of $c_{3}$ followed proton release $(50,51,58)$ and proton tautomerization (59) coupled to heme oxidation. A continuum electrostatics analysis was also carried out of de novo designed two heme four-helix bundle cytochromes (60).

Here, multiconformation continuum electrostatics (MCCE) $(30,33)$ is used to investigate cytochromes in four structural motifs with $E_{\mathrm{m}}$ 's varying by $450 \mathrm{mV}$. The comparison of the same reaction in different structures shows that each motif modifies the free energy of buried charges differently. Factors including the axial ligands, heme solvation energy, surface and buried charged groups, the dipoles of the protein backbone and side chains, changes in protein conformation and residue protonation, and solvent $\mathrm{pH}$ are all found to influence the free energy of heme oxidation and thus the calculated $E_{\mathrm{m}}$.

\section{METHODS}

MCCE Method. Multiconformation continuum electrostatics (MCCE) is a hybrid method combining continuum electrostatics and molecular mechanics $(11,30,61)$ (see ref 33 for a recent detailed description). Traditional continuum electrostatics calculations consider protein microstates that differ only in residue ionization (27-29). Other protein and solvent responses to charge changes are implicitly included in the parameter used for the continuum dielectric constant $(16,32,61)$. The higher the dielectric constant, the more motions are not considered explicitly $(32,39,61)$. Proteins are sufficiently flexible that a value of 20 has been needed for protein $(29,62)$. MCCE $(30,33)$ and related methods (63-67) add explicit side chain rotamers for polar and ionizable groups and buried water molecules. Rotamer sampling provides a position dependent response to changes in charge, and so a lower protein dielectric constant of 4 can be used. In MCCE side chains, cofactors and buried waters have preassigned conformers which differ in their protonation or oxidation state and their side chain rotamer and/or polar hydrogen position. Buried waters are treated in atomic detail, while surface waters with more than $10 \%$ solvent exposure defined by SURFV $(68,69)$ are deleted. Backbone and nonpolar side chains are not allowed to move.

The covalently bound heme propionic acids are treated as two independent ionizable residues. A new conformer library was designed to allow rotamer and ionization changes (Supporting Information Table 1). Starting with 18 rotamers, 2-4 remain after pruning those with unfavorable LennardJones interactions with protein. Each rotamer is given a neutral conformer with a hydrogen between the two oxygens (30), a favored position (70).

The free energy of a conformer considers its reaction field energy, torsion energy, and its pairwise interactions with fixed parts of the protein and with other conformers. DelPhi calculates all electrostatic energy components with the finite difference Poisson-Boltzmann equation (71). PARSE charges were used (72). The nonelectrostatic torsion (30) and Lennard-Jones parameters are from reference (33). Protein microstates are created given one conformer for each residue, cofactor, and buried water. The free energy of microstate $x$ $\left(\Delta G_{x}\right)$ is

$$
\begin{array}{r}
\Delta G_{x}=\sum_{i=1}^{M} \delta_{x}(i)\left\{\gamma ( i ) \left[2.3 k_{\mathrm{b}} T\left(\mathrm{pH}-\mathrm{p} K_{\mathrm{sol}, i}\right)-n F\left(E_{h}-\right.\right.\right. \\
\left.\left.E_{\mathrm{m}, \mathrm{sol}, i}\right)\right]+\left(\Delta \Delta G_{\mathrm{rxn}, i}+\Delta G_{\mathrm{torsion}, i}+\Delta G_{\mathrm{pol}, i}+\right. \\
\left.\left.\Delta G_{\mathrm{fixed}, i}^{\mathrm{nonel}}\right)\right\}+\sum_{i=1}^{M} \delta_{x}(i) \sum_{j=i+1}^{M} \delta_{x}(j)\left[\Delta G_{i j}^{\mathrm{el}}+\Delta G_{i j}^{\mathrm{nonel}}\right]
\end{array}
$$

The first terms account for the reference chemistry of the group in solution ( $\mathrm{p} K_{\mathrm{a}}$ and $\left.E_{\mathrm{m}}\right)$ and the solvent conditions $\left(\mathrm{pH}\right.$ and $\left.E_{\mathrm{h}}\right)$, the second for conformer self-energies and interactions with fixed portions of the protein, and the third interactions between conformers in the considered microstate. $k_{\mathrm{b}} T$ is $25 \mathrm{meV}\left(0.43 \Delta \mathrm{p} K_{\mathrm{a}}\right.$ units $=0.58 \mathrm{kcal} / \mathrm{mol}$ at $20^{\circ} \mathrm{C}$. $)$, $n$ the number of electrons gained or lost in redox reactions, $F$ the Faraday's constant, and $M$ the total number of conformers. $\delta_{x}(i)$ is 1 for selected conformers and 0 for all others. $\gamma(i)$ is 1 for bases, -1 for acids, and 0 for neutral conformers (polar groups, waters, neutral acids and bases). $\mathrm{p} K_{\mathrm{sol}, i}$ is the solution $\mathrm{p} K_{\mathrm{a}}$ of group $i, E_{\mathrm{m}, \text { sol }, i}$ the solution $E_{\mathrm{m}}$ for the heme-axial ligand complex, $\Delta \Delta G_{\mathrm{rxn}, i}$ the difference between the conformer reaction field energy in solution and protein (71), $\Delta G_{\text {torsion, } i}$ the conformer torsion energy, $\Delta G_{\mathrm{pol}, i}$ the conformer electrostatic interaction with the backbone dipoles, and $\Delta G_{\text {fixed }}^{\text {nonel }}$ the Lennard-Jones interaction with the backbone and side chains with no conformers. $\Delta G_{i j}^{\mathrm{el}}$ and $\Delta G_{i j}^{\text {nonel }}$ are pairwise interactions between side chain conformers $i$ and $j$. Strong pairwise electrostatic interaction are reduced using an empirical function (SOFT) (33). Monte Carlo sampling yields conformer occupancies in a Boltzmann distribution of states as a function of $E_{\mathrm{h}}$ and $\mathrm{pH}$. The midpoint potential $\left(E_{\mathrm{m}}\right)$ is the $E_{\mathrm{h}}$ where reduced and oxidized heme conformers are equally occupied.

Heme Parameters. The four heme ring nitrogen atoms have a -0.5 charge and the iron a +2 or +3 charge in the 


\begin{tabular}{|c|c|c|c|c|c|c|c|c|c|c|}
\hline label & cytochrome & source & motif & \# PDB & $\#$ res & ligand & exp. $E_{\mathrm{m}}$ & $E_{\mathrm{m}, \mathrm{sol}}$ & $-\Delta G_{\text {protein }} / n F$ & calc $E_{\mathrm{m}}$ \\
\hline 1 & $c_{2}$ & R. capsulatus & globin & 2 & 116 & His-Met & 350 & -15 & 294 & $279 \pm 22$ \\
\hline 2 & $c_{2}$ & R. viridis & globin & 2 & 107 & His-Met & 296 & -15 & 271 & $256 \pm 34$ \\
\hline 3 & $c$ & S. cerevisiae & globin & 2 & 108 & His-Met & 290 & -15 & 335 & $320 \pm 7$ \\
\hline 4 & $c$ & E. caballus & globin & 9 & 104 & His-Met & 260 & -15 & 234 & $219 \pm 64$ \\
\hline 5 & $c_{551}$ & P. aeruginosa & globin & 3 & 82 & His-Met & 270 & -15 & 232 & $217 \pm 17$ \\
\hline 6 & $c_{553}$ & B. pasteurii & globin & 1 & 71 & His-Met & 47 & -15 & 101 & 86 \\
\hline 7 & $b_{562}$ & E. coli & 4-helix & 3 & 106 & His-Met & 168 & -15 & 268 & $253 \pm 35$ \\
\hline 8 & $b_{5}$ & B. taurus (wt) & $\alpha / \beta$ & 2 & 82,93 & Bis-His & -10 & -220 & 134 & $-86 \pm 21$ \\
\hline \multirow[t]{2}{*}{9} & $b_{5}$ & Rattus N. (wt) & $\alpha / \beta$ & 2 & 94 & Bis-His & -102 & -220 & 119 & $-101 \pm 34$ \\
\hline & & & & & & & & \multicolumn{2}{|c|}{ RMSD } & 54 \\
\hline \multicolumn{11}{|c|}{ Mutants } \\
\hline $8^{\prime}$ & $b_{5}$ & B. taurus V61H & $\alpha / \beta$ & 1 & 82 & bis-His & 12 & -220 & 235 & 15 \\
\hline $9^{\prime}$ & $b_{5}$ & Rattus N. V45I/V61I & $\alpha / \beta$ & 2 & 86 & bis-His & -63 & -220 & 170 & $-50 \pm 1$ \\
\hline \multicolumn{11}{|c|}{ Cytochromes with no Exp. $E_{\mathrm{m}, \mathrm{sol}}$ for the Heme-Ligand Complex } \\
\hline 10 & $f$ & C. reinhardtii & $\beta$ & 6 & 251 & His $-\mathrm{Ntr}$ & 350 & $-13^{b}$ & 363 & $350 \pm 10$ \\
\hline 11 & $c^{\prime}$ & R. palustris & 4-helix & 2 & 125 & His & 94 & $-111^{b}$ & 224 & $113 \pm 15$ \\
\hline 12 & $c^{\prime}$ & R. capsulatus & 4-helix & 5 & 129 & His & 51 & $-111^{b}$ & 189 & $78 \pm 50$ \\
\hline 13 & $c^{\prime}$ & R. molischianum & 4-helix & 2 & 128 & His & 14 & $-111^{b}$ & 92 & $-19 \pm 9$ \\
\hline
\end{tabular}

${ }^{a}$ Labels: identifiers for points in Figure 2, 5, and 7. \# PDB: number of protein structures analyzed. Complete results for individual structures in Supporting Information Table 2. All $E_{\mathrm{m}}$ 's in $\mathrm{mV}$ vs SHE. $E_{\mathrm{m}, \mathrm{sol}}$ for His-Met and bis-His ligands obtained from earlier measurements as described in results; ${ }^{b}$ In cytochromes with no experimental values, $E_{\mathrm{m}, \mathrm{sol}}$ was estimated given the exp. $E_{\mathrm{m}}$ and the MCCE calculated $-\Delta G_{\mathrm{protein}} / n F(\mathrm{eq} 2)$. RMSD: root-mean-square deviation of the calculated from the experimental $E_{\mathrm{m}}$. Experimental $E_{\mathrm{m}}$ 's from: 1,5 (97), 2 (98), 3 (99), 4 (6), 6 (100), $7(41), 8,8^{\prime}(85), 9(101), 9^{\prime}(96), 10(4), 11,12,13(102)$. The uncertainty of the experimental midpoints is $\approx \pm 30 \mathrm{mV}(5,103) .-\Delta G_{\text {protein }} / n F$ : MCCE calculated shift in $E_{\mathrm{m}, \mathrm{sol}}$ due to the protein $(\mathrm{mV})$ (Table 2). Calc $E_{\mathrm{m}}: E_{\mathrm{m}}$ calculated with eq 2.

reduced or oxidized state (8). Ligand backbone atoms are treated as other protein amides while their side chain atoms have no charge. The influence of the side chain on the heme is included in $E_{\mathrm{m}, \text { sol. }}$. More realistic heme charges are available $(58,73)$. The sensitivity of the outcome to the charge distribution was tested by assigning +1.0 and +1.6 to the iron with the 20 outer atoms sharing -1.0 and -0.6 charge for reduced and oxidized states, respectively. Changing the charges changed the $E_{\mathrm{m}}$ 's by less than $50 \mathrm{mV}$ in calculations of seven cytochromes in four structural motifs.

MCCE calculates the difference in free energy of ionizing a heme-ligand complex in protein and solvent. The reaction field energy in solvent was precalculated with DelPhi for the heme with its two amino acid axial ligands plus backbone, with no propionic acids. It is $-430 \mathrm{meV}$ for oxidized and $-20 \mathrm{meV}$ for reduced heme with either HisMet and bis-His ligands (8).

Dielectric Boundary in MCCE Calculations. As described previously (33), conformers added to surface residues such as the propionic acids erroneously increase the low dielectric region in the DelPhi calculations. Two cycles of MCCE were run with the second including only conformers that were occupied in the first calculation. This changed the calculated $E_{\mathrm{m}}$ 's by less than $20 \mathrm{mV}$, indicating that the default MCCE corrections for the extra conformers are adequate. The data presented here use the second calculation with fewer extra conformers.

Contribution of Residues to the Free Energy of Heme Oxidation. In the protein equilibrated around the oxidized heme (Prot*) at a given $\mathrm{pH}$, the contribution of a residue to the free energy of heme oxidation, $\Delta G_{\text {res }, i}^{\text {Pro* }}$, is

$$
\Delta G_{\mathrm{res}, i}^{\text {Pro** }}=\sum_{c=1}^{\text {allconf }} \rho_{i c}^{\text {prot* }^{*}}\left(E_{i c, \mathrm{Hem}^{+}}-E_{i c, \mathrm{Hem}}\right)
$$

$\rho_{i c}^{\text {prot* }}$ is the Boltzmann occupancy of conformer $c$ of residue $i$ in the oxidized protein, $E_{i c, \mathrm{Hem}^{+}}$the interaction energy of that conformer with the oxidized, and $E_{i c, \text { Hem }}$ the reduced heme. The interaction of all residues with the heme, $\Delta G_{\text {res }}^{\text {Pro* }}$, sums $\Delta G_{\text {res, } i}^{\text {Pro* }}$ over all residues. A similar expression $\Delta G_{\text {res }}^{\text {Prot }}$ for protein equilibrated around the reduced heme (Prot) can be obtained using $\rho_{\mathrm{ic}}^{\text {prot }}$, the occupancy of residues in Prot.

\section{RESULTS}

Electrochemical midpoint potentials, $E_{\mathrm{m}}$ 's, were calculated at $\mathrm{pH} 7$ for 13 cytochromes in globin $\left(c, c_{2}, c_{551}, c_{553}\right)$, fourhelix bundle $\left(c^{\prime}, b_{562}\right), \alpha \beta$ roll $\left(b_{5}\right)$, and $\beta$ sandwich $(f)$ motifs (Table 1). These cytochromes have $E_{\mathrm{m}}$ 's from $-100\left(b_{5}\right)$ to $+350\left(f\right.$ and $\left.c_{2}\right) \mathrm{mV}$, representing about $60 \%$ of the total range for cytochromes $(4,5)$. The $\beta$ cytochrome $f$ is near the highest potential $(350 \mathrm{mV})$, the globin $E_{\mathrm{m}}$ 's range from $50\left(c_{553}\right)$ to $350\left(c_{2}\right) \mathrm{mV}$, the four-helix bundles range from $15\left(c^{\prime}\right)$ to $170\left(b_{562}\right) \mathrm{mV}$, and the $\alpha \beta b_{5}$ 's are at low potentials $(-100$ to $-10 \mathrm{mV})$. Two mutants of cytochrome $b_{5}$ are studied to investigate how modest changes in structure modify electrochemistry. Crystal and NMR structures in different oxidation states and at different $\mathrm{pH}$ or ionic strength were analyzed wherever available and the results averaged. In total, 44 data files were analyzed (Supporting Information Table 2).

Calculated Cytochrome $E_{\mathrm{m}}$ 's for Heme-Ligand Complexes with Established Reference $E_{m}$ 's. MCCE calculates the shift in the free energy of ionization as the heme is moved from water into the protein $\left(\Delta G_{\text {protein }}\right)$. This provides the cytochrome $E_{\mathrm{m}}$ given:

$$
E_{\mathrm{m}}=E_{\mathrm{m}, \mathrm{sol}}-\Delta G_{\text {protein }} / n F
$$

All $E_{\mathrm{m}}$ 's and $\Delta G$ s are for a standard state at $\mathrm{pH} 7\left(E_{\mathrm{m}}{ }^{\circ \prime}\right.$ and $\left.\Delta G^{\circ}\right)$. The reference $E_{\mathrm{m} \text {,sol }}$ is for an isolated heme with given axial ligands in water. While $E_{\mathrm{m}, \mathrm{sol}}$ is not as certain as $\mathrm{p} K_{\mathrm{a}, \mathrm{sol}}$ of the amino acids, $E_{\mathrm{m}}$ 's of microperoxidases, hemes 


\begin{tabular}{|c|c|c|c|c|c|c|c|c|c|c|c|}
\hline label & cyt & $\Delta \Delta G_{\mathrm{rxn}}$ & $\Delta G_{\mathrm{pol}}$ & $\Delta G_{\text {prop }}^{\text {Prot }}$ & $\Delta G_{\text {prop }}^{\text {Prot* }}$ & $\Delta G_{\mathrm{res}}^{\text {Prot }}$ & $\Delta G_{\mathrm{res}}^{\mathrm{Pros}^{*}}$ & $\Delta G_{\text {Prot } \rightarrow \text { Prot* }}^{\text {red }}$ & $\Delta G_{\mathrm{Prot} \rightarrow \text { Prot* }}^{\mathrm{ox}}$ & $\begin{array}{l}\% \text { prop } \\
\text { ioniz }\end{array}$ & $\begin{array}{l}\% \text { prop } \\
\text { ioniz }^{\text {ox }}\end{array}$ \\
\hline 1 & $c_{2}$ & $244 \pm 2$ & $152 \pm 2$ & $-75 \pm 34$ & $-164 \pm 5$ & $35 \pm 13$ & $3 \pm 9$ & $58 \pm 12$ & $-62 \pm 21$ & $33 \pm 15$ & $64 \pm 4$ \\
\hline 2 & $c_{2}$ & $256 \pm 3$ & $140 \pm 21$ & $-142 \pm 16$ & $-270 \pm 12$ & $100 \pm 1$ & $70 \pm 24$ & $75 \pm 23$ & $-83 \pm 6$ & $53 \pm 8$ & $94 \pm 4$ \\
\hline 3 & $c$ & $258 \pm 1$ & $125 \pm 5$ & $-138 \pm 1$ & $-180 \pm 30$ & $132 \pm 11$ & $92 \pm 5$ & $40 \pm 12$ & $-42 \pm 3$ & $50 \pm 0$ & $63 \pm 10$ \\
\hline 4 & $c$ & $251 \pm 8$ & $131 \pm 16$ & $-126 \pm 38$ & $-201 \pm 64$ & $40 \pm 30$ & $-3 \pm 29$ & $56 \pm 27$ & $-62 \pm 17$ & $51 \pm 11$ & $78 \pm 18$ \\
\hline 5 & $c_{551}$ & $205 \pm 25$ & $85 \pm 41$ & $-95 \pm 3$ & $-132 \pm 40$ & $79 \pm 27$ & $9 \pm 12$ & $66 \pm 5$ & $-41 \pm 3$ & $51 \pm 2$ & $68 \pm 19$ \\
\hline 6 & $c_{553}$ & 223 & -3 & -49 & -60 & -61 & -64 & 5 & -9 & 41 & 50 \\
\hline 7 & $b_{562}$ & $192 \pm 7$ & $18 \pm 13$ & $-40 \pm 31$ & $-72 \pm 31$ & $118 \pm 18$ & $113 \pm 16$ & $18 \pm 6$ & $-20 \pm 2$ & $45 \pm 25^{b}$ & $71 \pm 24^{b}$ \\
\hline 11 & $c^{\prime}$ & $156 \pm 3$ & $48 \pm 2$ & $-140 \pm 6$ & $-141 \pm 5$ & $164 \pm 26$ & $158 \pm 25$ & $4 \pm 0$ & $-3 \pm 0$ & $99 \pm 1$ & 100 \\
\hline 12 & $c^{\prime}$ & $163 \pm 15$ & $26 \pm 11$ & $-146 \pm 23$ & $-155 \pm 15$ & $158 \pm 36$ & $144 \pm 40$ & $11 \pm 5$ & $-12 \pm 8$ & $91 \pm 14$ & 97 \\
\hline 13 & $\mathrm{c}^{\prime}$ & $133 \pm 3$ & $9 \pm 3$ & $-159 \pm 28$ & $-166 \pm 23$ & $114 \pm 11$ & $110 \pm 10$ & $5 \pm 0$ & $-5 \pm 2$ & $95 \pm 6$ & 99 \\
\hline 8 & $b_{5}$ & $161 \pm 3$ & $132 \pm 12$ & $-101 \pm 33$ & $-147 \pm 61$ & $-40 \pm 8$ & $-41 \pm 6$ & $29 \pm 24$ & $-19 \pm 5$ & $94 \pm 2$ & 100 \\
\hline 9 & $b_{5}$ & $188 \pm 8$ & $43 \pm 9$ & $-70 \pm 13$ & $-90 \pm 24$ & $-31 \pm 1$ & $-38 \pm 0$ & $16 \pm 7$ & $-11 \pm 3$ & $84 \pm 4$ & 95 \\
\hline 10 & $f$ & $236 \pm 2$ & $173 \pm 3$ & $-171 \pm 3$ & $-171 \pm 3$ & $136 \pm 9$ & $110 \pm 12$ & $17 \pm 7$ & $-9 \pm 2$ & $100 \pm 0$ & 100 \\
\hline $\begin{array}{l}8^{\prime} \\
9^{\prime}\end{array}$ & $\begin{array}{l}b_{5} \\
b_{5}\end{array}$ & $\begin{array}{c}162 \\
195 \pm 9\end{array}$ & $\begin{array}{c}114 \\
108 \pm 16\end{array}$ & $\begin{array}{c}-73 \\
-58 \pm 2\end{array}$ & $\begin{array}{c}-84 \\
-69 \pm 3\end{array}$ & $\begin{array}{c}\text { Mutants } \\
44 \\
-70 \pm 8\end{array}$ & $\begin{array}{c}23 \\
-72 \pm 8\end{array}$ & $\begin{array}{c}21 \\
8 \pm 3\end{array}$ & $\begin{array}{c}-11 \\
-5 \pm 1\end{array}$ & $\begin{array}{c}98 \\
83 \pm 8\end{array}$ & $\begin{array}{c}100 \\
95 \pm 3\end{array}$ \\
\hline \multicolumn{12}{|c|}{ Average for Each Motifs (Without Mutants) } \\
\hline globin & & $239 \pm 19$ & $105 \pm 53$ & $-104 \pm 34$ & $-168 \pm 64$ & $54 \pm 62$ & $18 \pm 51$ & $50 \pm 23$ & $-50 \pm 23$ & $47 \pm 7$ & $70 \pm 14$ \\
\hline four-h & & $161 \pm 21$ & $25 \pm 14$ & $-121 \pm 47$ & $-134 \pm 37$ & $138 \pm 23$ & $13 \pm 201$ & $10 \pm 5$ & $-10 \pm 7$ & $95 \pm 3$ & $99 \pm 1$ \\
\hline$\alpha / \beta$ & & $175 \pm 14$ & $87 \pm 45$ & $-85 \pm 15$ & $-118 \pm 29$ & $-36 \pm 4$ & $-40 \pm 1$ & $23 \pm 6$ & $-15 \pm 4$ & $89 \pm 5$ & $98 \pm 3$ \\
\hline$\beta$ & & 236 & 173 & -171 & -171 & 136 & 110 & 17 & -9 & 100 & 100 \\
\hline
\end{tabular}

${ }^{a} \Delta G$ 's in meV. Label: protein identifiers from Table 1. Averaged values and standard deviations given for different structures of each protein. Results for each structure in Supporting Information, Table 2. $\Delta \Delta G_{\text {Ixn }}$ : loss of reaction field energy when heme-ligand complex is transferred from water $(\epsilon=80)$ to protein $(\epsilon=4)$. Reference, solution $\Delta G_{\mathrm{rxn}, \mathrm{sol}}$ is $-430 \mathrm{meV}$ for oxidized and $-20 \mathrm{meV}$ for reduced heme. $\Delta G_{\mathrm{pol}}$ : pairwise

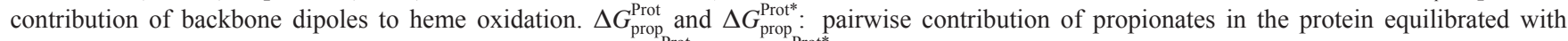
reduced (Prot) and oxidized (Prot*) heme (Figure 5). $\Delta G_{\text {res }}^{\text {Prot }}$ and $\Delta G_{\text {res }}^{\text {Prot* }}$ : pairwise contributions of side chains and buried waters (eq 2). $\Delta G_{\text {Prot } \rightarrow \text { Prot* }}^{\text {red }}$ and $\Delta G_{\text {Prot } \rightarrow \text { Prot* }}^{\text {ox }}:$ energy change moving from Prot to Prot* in the presence of reduced (red) or oxidized (ox) heme (eq 6, Fig, 3). \% prop ioniz: the percentage of the two propionates ionized at $\mathrm{pH} 7$ in the reduced or oxidized protein. ${ }^{b}$ Propionic acid ionization for $b_{562}$ without chain A of $256 \mathrm{~b}$ is $59 \%$ in Prot and $86 \%$ in Prot*.

associated with 8 (MP8) or 11 (MP11) residue peptides, have been measured $(45,74-78)$. $E_{\mathrm{m}, \mathrm{sol}}$ of bis-His MPs ranges from -190 (45) to -220 (76) $\mathrm{mV}$ (vs S.H.E.). His-Met MP's have $E_{\mathrm{m}, \mathrm{sol}}$ from $120(45)$ to $170(76,79) \mathrm{mV}$ more positive than those of bis-His MPs. The $\Delta E_{\mathrm{m}, \mathrm{sol}}\left(\mathrm{E}_{\mathrm{m}, \mathrm{sol}}\right.$ difference) between His-Met and bis-His hemes may be bigger in MP8 than MP11 (45). There have also been studies where the liganding Met is mutated to His in cytochrome $c$ $(80,81)$ and $\mathrm{c}_{551}(82)$. The mutated bis-His cytochrome has an $E_{\mathrm{m}} 205(81)$ to $220 \mathrm{mV}$ (82) lower than the wild-type protein, a larger shift than that found in the MP's for the same ligand change.

$E_{\mathrm{m}}$ 's were calculated for the nine wild-type cytochromes with bis-His or His-Met ligands and compared with the experimental values (Table 1, Figure 2a). Using MP values, of -220 for bis-His and -70 for His - Met hemes $\left(\Delta E_{\mathrm{m}}\right.$ of $150 \mathrm{mV}$ ), the root-mean-square deviation (RMSD) between the experimental and calculated $E_{\mathrm{m}}$ is $77 \mathrm{mV}$. The slope comparing experimental and calculated values is 0.8 , and seven of the nine calculated values are lower than predicted. This is not bad, considering that there are no free parameters. However a better match to the data can be found by increasing $\Delta E_{\mathrm{m} \text {,sol }}$ to -205 , the value found for ligand exchange by mutation in cytochromes $(81,82)$. With $E_{\mathrm{m}, \mathrm{sol}}$ 's of -220 for bis-His and -15 for His - Met, the RMSD for the nine cytochromes is $54 \mathrm{mV}$ and the slope 0.90 . All but three of the $E_{\mathrm{m}}$ 's are within $60 \mathrm{mV}$ of the experimental values.

Deriving $E_{m, \text { sol }}$ for Additional Heme-Ligand Complexes. There are no measured reference potentials for the HisNter ligated $f$ and single His, five-coordinate $c^{\prime}$ hemes. $E_{\mathrm{m}, \mathrm{sol}}$ can be back-calculated, given the experimental $E_{\mathrm{m}}$ and the
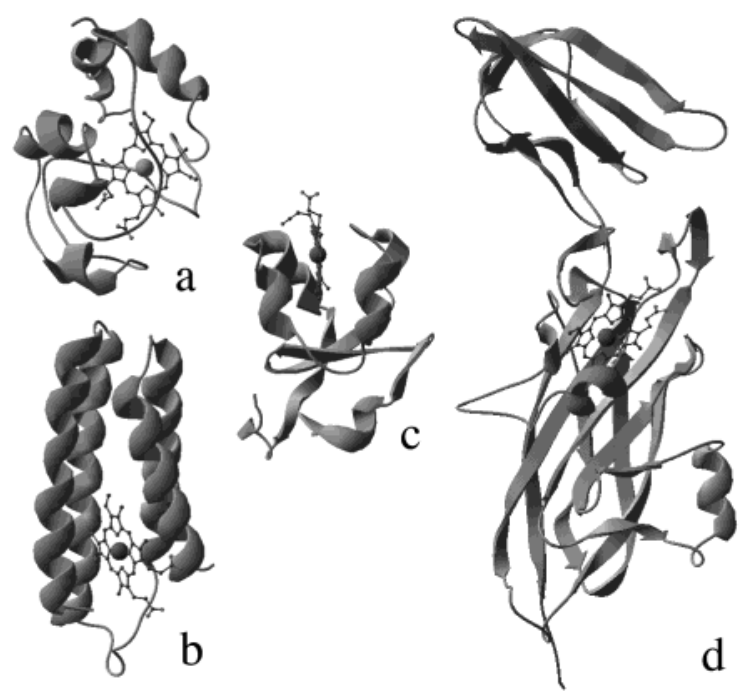

FIGURE 1: Cytochrome motifs. (a) Globin (E. caballus cyt c 1GIW). (b) Four-helix bundle (E. coli cyt $b_{562} 256 \mathrm{~B}$ chain B). (c) $\alpha \beta$ (B. taurus cyt $b_{5} 1 \mathrm{CYO}$ ). (d) $\beta$ sandwich (C. reinhardtii cyt $f 1 \mathrm{EWH}$ chain A).

calculated protein modulation of the reaction free energy, $\Delta G_{\text {protein, }}$ (eq 3). This yields $E_{\mathrm{m}, \text { sol }}$ of $-13 \mathrm{mV}$ for the HisNter heme and $-111 \mathrm{mV}$ for the five-coordinate His heme (Table 1).

Terms Contributing to in Situ $E_{\mathrm{m}}$ 's. A breakdown of $\Delta G_{\text {redox }}$, considering either path around the thermodynamic box (Figure 3), shows how each protein modulates heme electrochemistry:

$$
\begin{array}{r}
\Delta G_{\mathrm{redox}}=-n F E_{\mathrm{m}}=\Delta G_{\mathrm{red} \rightarrow \mathrm{ox}}^{\mathrm{Prot}}+\Delta G_{\mathrm{Prot} \rightarrow \mathrm{Prot}^{*}}^{\mathrm{Px}}= \\
\Delta G_{\mathrm{Prot}^{\mathrm{red}} \rightarrow \mathrm{Prot}^{*}}+\Delta G_{\mathrm{red} \rightarrow \mathrm{ox}}^{\mathrm{Prot}^{*}}
\end{array}
$$




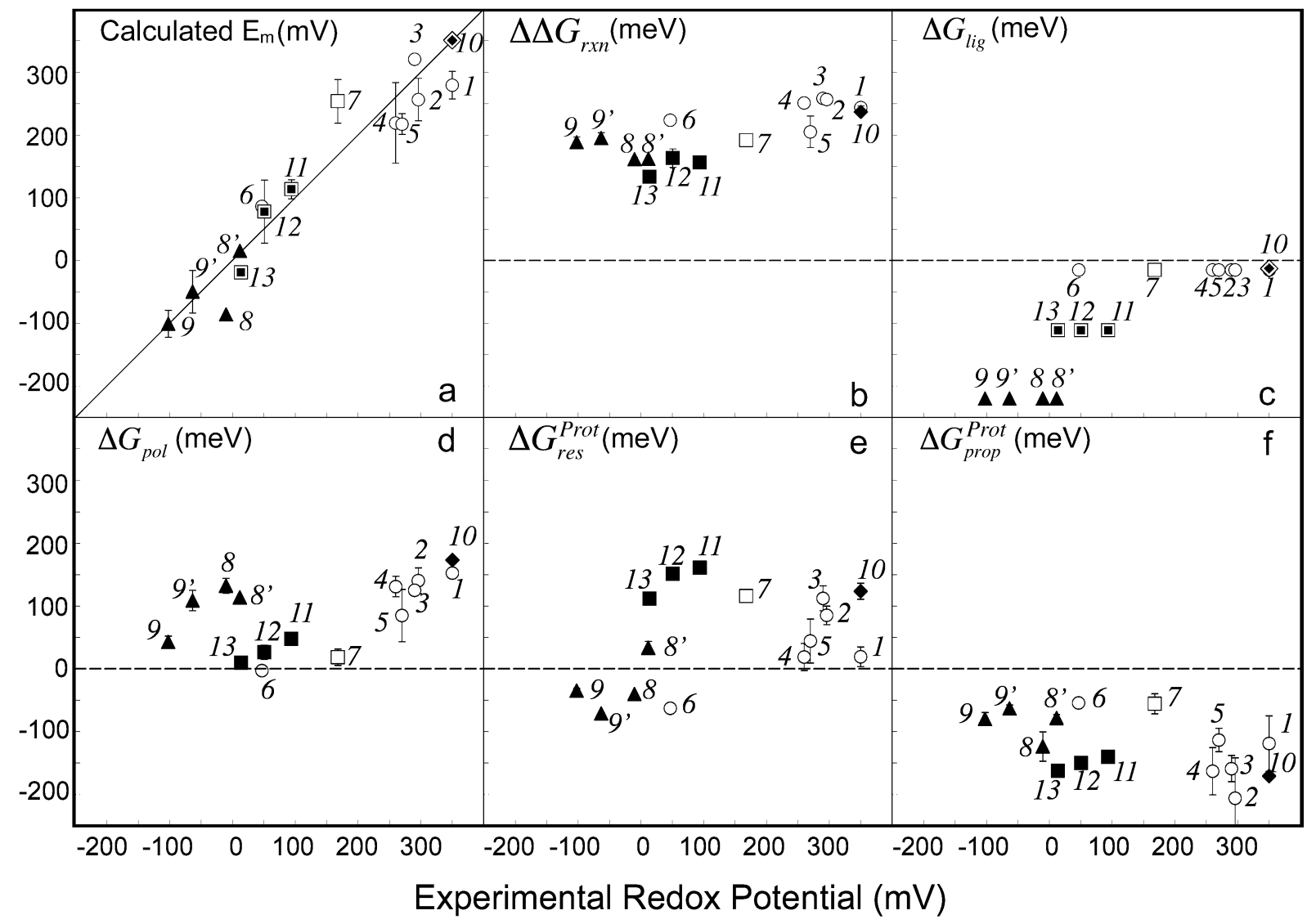

FIGURE 2: MCCE calculated $E_{\mathrm{m}}$ and factors contributing to the heme redox potential. (a) Calculated vs experimental $E_{\mathrm{m}}(\mathrm{mV})$. Error bars are standard deviation of values from different structures. Solid line where experimental and calculated $E_{\mathrm{m}}$ 's are equal (Table 1). (b-e) Contributors to $\Delta G_{\text {redox }}(\mathrm{meV})$ vs experimental $E_{\mathrm{m}}(\mathrm{mV})$ (Table 2, eq 4); (b) $\Delta \Delta G_{\mathrm{rxn}}$, loss of reaction field energy; (c) $\Delta G_{\text {lig, ligand contribution }}$ $\left(-n F E_{\mathrm{m}, \mathrm{sol}}{ }^{\circ}\right)$; (d) $\Delta G_{\mathrm{pol}}$, interaction with backbone dipoles. Pairwise interactions in protein equilibrated with reduced heme: (e) $\Delta G_{\text {res }}^{\text {Prot }}$ with amino acid side chains; (f) $\Delta G_{\text {prop }}^{\text {Prot }}$ with propionic acids. Globins: $(O) \mathrm{c}(S$. cerevisiae 3, E. caballus 4$), c_{2}(R$. capsulatus $1, R$. viridis 2$)$, $c_{551}$ (P. Aeruginosa 5), $c_{553}$ (B. pasteurii 6). Four-helix bundles: ( $\square$ ) $b_{562}($ E. coli $(7)),(\square) c^{\prime}(R$. palustris $11, R$. capsulatus $12, R$. molischianum 13). $\alpha \beta$ 's $(\mathbf{\Delta}) b_{5}$ (B. taurus $8,8^{\prime}$, Rattus $N .9,9^{\prime} ; \beta$ sandwich $(\diamond) f(C$. reinhardtii 10$)$. The same symbols and numerical labels will be used in later figures. Points in panels a and c: solid, bis-His hemes; clear, His-Met hemes; points 10-13, five-coordinate or His-Ntr with $E_{\mathrm{m}, \text { sol }}$ derived here. In other figures: clear, His-Met hemes; solid, all others. $Y$ axis units are: $\mathrm{a}, \mathrm{mV} ; \mathrm{b}-\mathrm{f}, \mathrm{meV}$.

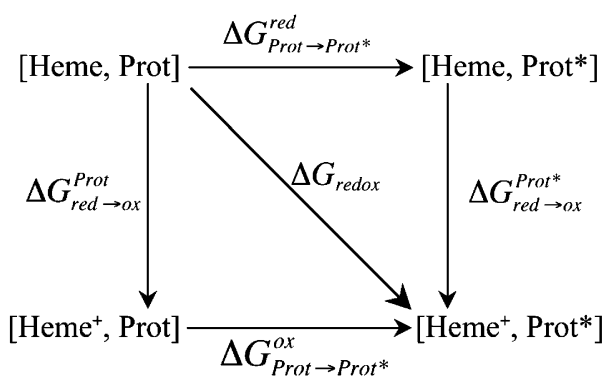

FiguRE 3: Thermodynamic box for the redox reaction [Heme, Prot] $\rightarrow\left[\mathrm{Heme}^{+}\right.$, Prot*]. Diagonal $\Delta G_{\text {redox }}$ is the outcome of MCCE calculations (eq 4). Lower triangle (eqs 4-6): the heme is oxidized first in the reduced, equilibrated protein $\left(\Delta G_{\mathrm{red} \rightarrow \mathrm{ox}}^{\text {Prot }}\right)$; the reduced protein relaxes to the oxidized configuration $\left(\Delta G_{\mathrm{Prot} \rightarrow \mathrm{Prot}^{*}}^{\mathrm{ox}}\right)$. Upper triangle: the protein is first changed to the conformation equilibrated in the oxidized state keeping the heme reduced $\left(\Delta G_{\text {Prot } \rightarrow \text { Prot* }}^{\text {red }}\right)$; the heme is then oxidized $\left(\Delta G_{\mathrm{red} \rightarrow \mathrm{ox}}^{\mathrm{Prot}^{*}}\right)$.

MCCE calculates $\Delta G_{\text {redox }}$ (the diagonal), where side chain and propionic acid position and ionization states remain in equilibrium with the heme redox state. In the lower triangle, the heme is oxidized in an equilibrated, reduced protein $\left(\Delta G_{\mathrm{red} \rightarrow \mathrm{ox}}^{\mathrm{Prot}}\right)$, followed by favorable protein relaxation $\left(\Delta G_{\mathrm{Prot} \rightarrow \mathrm{Prot}^{*}}^{\mathrm{ox}}\right)$. Alternately, the protein is changed to its oxidized form (Prot*) with heme reduced $\left(\Delta G_{\text {Prot } \rightarrow \text { Prot* }}^{\text {red }}\right)$, an energy requiring process, followed by heme oxidation in the prepared Prot* $\left(\Delta G_{\mathrm{red} \rightarrow \mathrm{ox}}^{\text {Pro* }}\right)$. The energy of oxidation, with the system equilibrated in the reduced protein (lower path), can be divided (Table 2, Figure 3):

$$
\begin{aligned}
& \Delta G_{\mathrm{red} \rightarrow \mathrm{ox}}^{\text {Prot }}=-n F E_{\mathrm{m}, \mathrm{sol}}+\left(\Delta \Delta G_{\mathrm{rxn}}\right.\left.+\Delta G_{\mathrm{pol}}\right)+ \\
&\left(\Delta G_{\mathrm{res}}^{\text {Prot }}+\Delta G_{\mathrm{prop}}^{\text {Prot }}\right)
\end{aligned}
$$

All terms represent the free energy difference between the oxidized and reduced heme-ligand complex: $\Delta \Delta G_{\mathrm{rxn}}$ is the loss in reaction field (solvation) energy when the heme is moved from water to its position in the protein; $\Delta G_{\mathrm{pol}}$ is the pairwise interaction of heme with protein backbone amide dipoles. These terms are independent of the conformer distributions. $\Delta G_{\text {prop }}^{\text {Prot }}$ is the pairwise interactions of heme with the propionic acids and $\Delta G_{\text {res }}^{\text {Prot }}$ the interactions with protein side chains and buried waters in the reduced protein (eq 2). The energy needed to change the protein from reduced to oxidized conformation in the presence of the oxidized heme is (bottom transition Figure 3):

$$
\Delta G_{\text {Prot } \rightarrow \text { Prot* }}^{\mathrm{ox}}=\Delta G_{\text {redox }}-\Delta G_{\mathrm{red} \rightarrow \mathrm{ox}}^{\mathrm{Prot}}
$$

$\Delta \Delta G_{r x n}$ : The Loss in Reaction Field Energy. Moving out of water destabilizes the oxidized more than the reduced 


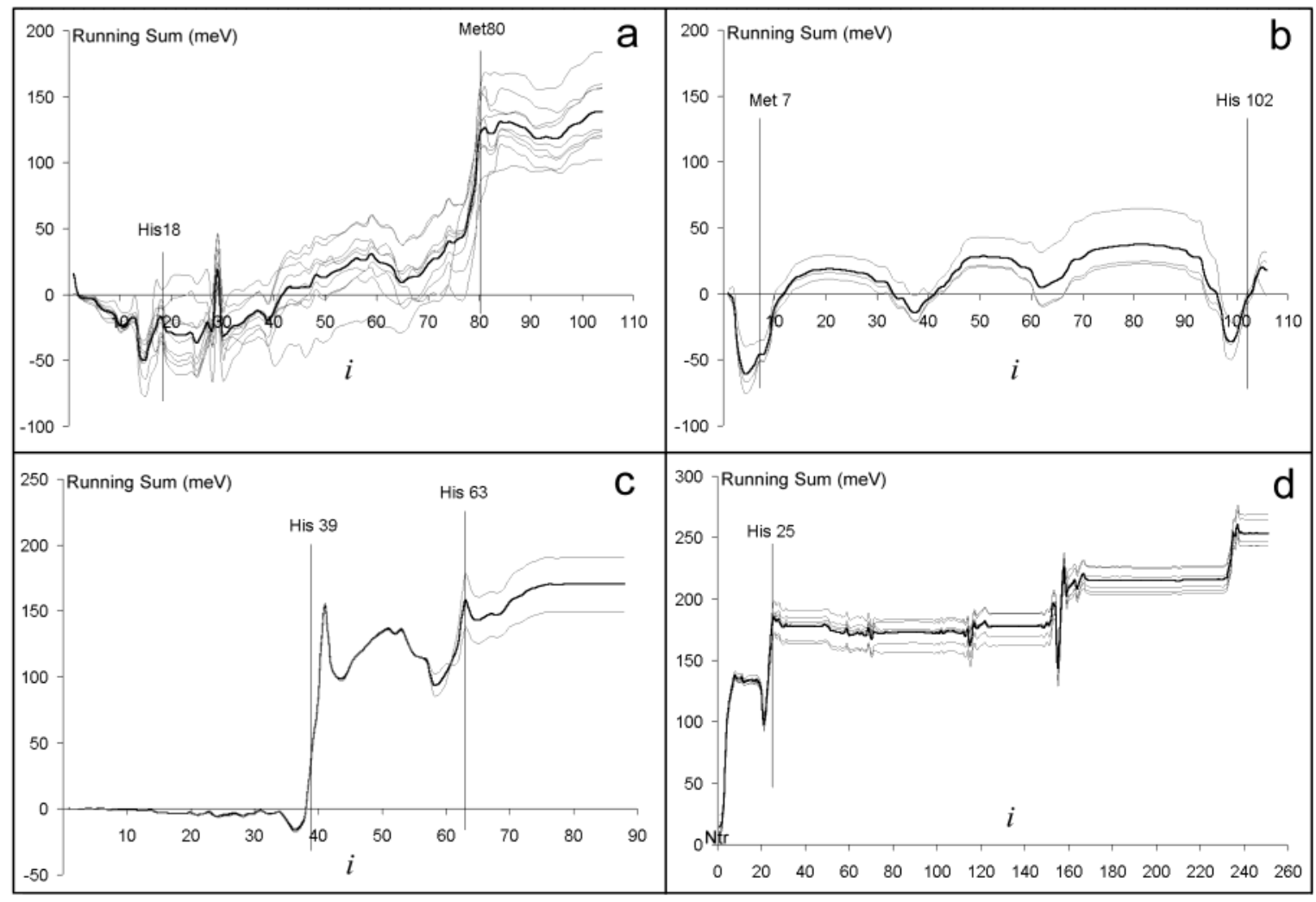

FIGURE 4: Contribution of each backbone amide to $\Delta G_{\mathrm{pol}}$. Running sum of interaction of heme with the amides from all residues up to and including residue $i$ is $\sum_{j=1}^{i} \Delta G_{\text {pol }, j}$. (a) Globin (E. caballus c); (b) four-helix bundle (E. coli b562); (c) $\alpha \beta$ roll (B. taurus b5); (d) $\beta$ (C. reinhardtii $f$ ). Thin lines: results for individual structures. Thick line: average value. Vertical lines: positions of heme ligands.

heme, raising the midpoint potential by $\Delta E_{\mathrm{m}, \mathrm{rxn}}=-\Delta \Delta G_{\mathrm{rxn}} /$ $n F \mathrm{mV}(53,54) . \Delta \Delta G_{\text {rxn }}$ ranges from 135 (Rhodospirillum molischianum $c^{\prime}$ ) to $260 \mathrm{meV}$ (yeast $c, R$. viridis $c_{2}$ ) (Figure 2b). $\Delta \Delta G_{\text {rxn }}$ raises the $E_{\mathrm{m}} \sim 70 \mathrm{mV}$ more in the globins and $\beta$ sandwich $f$ than it does in the $\alpha \beta b_{5}$ 's or four-helix bundles where the heme is closer to the protein surface (Table 2).

$\Delta G_{p o l}$ : Pairwise Interactions with the Protein Backbone. Heme oxidation is destabilized by $0-170 \mathrm{meV}$ by interactions with the backbone amide dipoles (Figure 2d, Table 2). The four-helix bundles have the smallest $\Delta G_{\mathrm{pol}}(25 \pm 14$ $\mathrm{meV}$ ), followed by the $\alpha \beta$ motif ( $87 \pm 45 \mathrm{meV}$ ), globins $(105 \pm 53 \mathrm{meV})$, and $\beta$ sandwich $(173 \mathrm{meV})$. The important regions can be identified by the running sum of the contribution to $\Delta G_{\mathrm{pol}}$ from each amide (Figure 4). The most important segments are always near the ligands. The amides of the ligands destabilize oxidation by 0 to $+40 \mathrm{meV} . \Delta G_{\mathrm{pol}}$ from the ligand amide \pm 2 residues can be as large as 100 $\mathrm{meV}$, as seen by the region around Met 80 in horse heart cytochrome $c$ (Figure 4a) and His 39 in the bovine $b_{5}$ (Figure $4 \mathrm{c})$. In each case the important amide HNs point in toward the heme. In $c_{553}$, where $\Delta G_{\mathrm{pol}}$ is near zero the residues on either side of the Met ligand form a small $\beta$-turn with the amides lying parallel to the heme. Similarly, the ligand amides in the four-helix bundles influence $\Delta G_{\mathrm{pol}}$ little because they are hydrogen bonded and oriented parallel to the heme plane. In the $\alpha / \beta b_{5}$ 's, the liganding amino acids are in turns at the top of four helices, with the loop amide dipoles raising the potential at the heme. The helix dipole contribution can be seen by a decrease and increase in the running sum. In general, helices contribute little to $\Delta G_{\mathrm{pol}}$. The exception is in cytochrome $f$, where the heme ligand is the N-terminus of an eight-residue helix, which raises the potential, destabilizing oxidation by $140 \mathrm{meV}$.

$\Delta G_{\text {res }}$ and $\Delta G_{\text {prop }}$ : Pairwise Interactions of the Heme with Side Chains, Propionic Acids and Buried Waters. The acidic, basic, and polar groups in the protein modify the heme $E_{\mathrm{m}}$ through pairwise electrostatic interactions. These can vary with $\mathrm{pH}$ and heme oxidation state as residues change position and gain or lose protons. There are more then 400 ionizable residues in the 13 cytochromes studied. Of the Asp, Glu, Arg, and Lys, $95 \%$ are more than $90 \%$ ionized at $\mathrm{pH} 7$ (Supporting Information Table 3). Rhodobacter capsulatus cytochrome $c^{\prime}$ is an exception with five of the $10 \mathrm{Glu}$ 's partially neutral. The majority of His are less than $50 \%$ ionized, while all Tyr are neutral. With the exception of the small $c_{553}$ and $b_{5}, \Delta G_{\text {res }}$ is positive destabilizing the oxidized state (Table 2 and Figure 2e). In the reduced protein, $\Delta G_{\text {res }}^{\text {Prot }}$ ranges from $-60\left(c_{553}\right)$ to $165\left(c^{\prime}\right) \mathrm{meV}$. Much of the $E_{\mathrm{m}}$ difference among the globins comes from the $190 \mathrm{meV}$ range of $\Delta G_{\text {res }}^{\text {Prot }} \Delta G_{\text {res }}^{\text {Prot* }}$ is more favorable than $\Delta G_{\text {res }}^{\text {Prot }}$, as the protein reorganizes to stabilize the oxidized heme. The difference between $\Delta G_{\text {res }}^{\mathrm{Prot}}$ and $\Delta G_{\mathrm{res}}^{\mathrm{Prot}^{*}}$ is small in four-helix bundles and $b_{5}$ and larger in $f(25 \mathrm{meV})$. The changes in globins vary from $5\left(c_{553}\right)$ to $70\left(c_{551}\right) \mathrm{meV}$.

Despite the large number of ionizable residues, only a few shift $\Delta G_{\text {res }}$ significantly (Supporting Information Table 4). No residues in the small $c_{553}$ or $b_{5} \operatorname{shift} \Delta G_{\text {res }}^{\text {Prot }}$ or $\Delta G_{\text {res }}^{\text {Prot }}$ by as much as $30 \mathrm{meV}$ because all charged and polar groups are near the surface and screened by solvent. Although there are fewer Arg than Lys in these cytochromes, Arg's contribute more since they are more often buried (23). Buried 


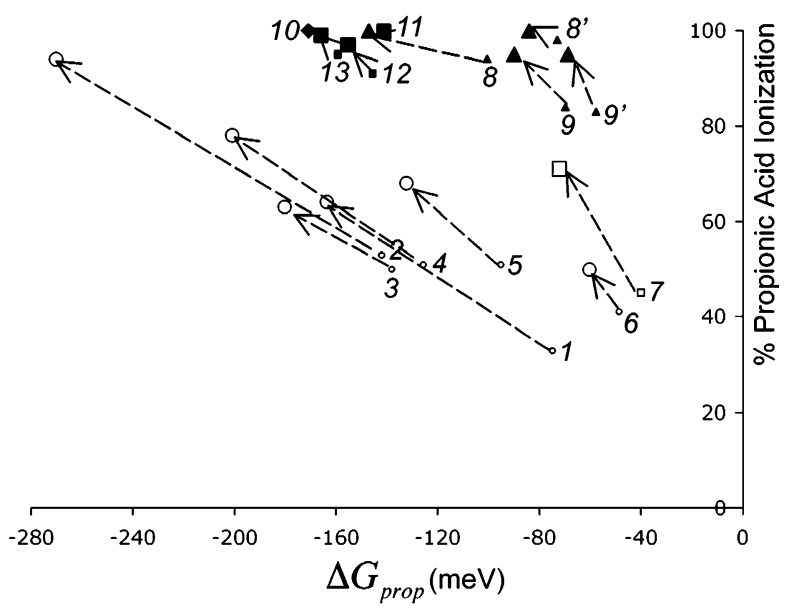

FiguRE 5: Propionic acid ionization vs $\Delta G_{\text {prop }}$ in reduced and oxidized protein. Small symbols calculated in reduced (Prot) protein. Larger symbols for structure equilibrated with oxidized heme (Prot*). Data from Table 2. Labels from Table 1, symbols are the same as those in Figure 3. 1-6, globins; 7 and 11-13, four-helix bundles; 8 and $9, \alpha \beta$ roll; $10, \beta$ sandwich.

polar residues such as Tyr (cyt $c$ ) and Asn (cyt $f$ and $c$ ) can also have significant interactions with the heme. Buried waters are treated in atomic detail in MCCE and included in $\Delta G_{\text {res }}(33)$. Although buried waters are found in $b_{562}, c$, and $f$, none contributes as much as $30 \mathrm{meV}$ to $\Delta G_{\text {res }}^{\text {Prot }}$. A mutant bovine $b_{5}(83)$ that substitutes an ionizable residue (His) for a nonpolar one (Val) was studied here $(83,84)$. The V61H mutant has a $\Delta E_{\mathrm{m}}$ of $22 \mathrm{mV}(85)$, while MCCE calculates a large $100 \mathrm{mV}$ shift. The primary error appears to be that MCCE predicts the His to be $80 \%$ ionized raising the $E_{\mathrm{m}}$ by $70 \mathrm{meV}$. This error shows the importance of the combined calculation of the residue ionization and heme redox potential.

Each heme has two covalently bound propionic acids with carboxylate groups about $8 \AA$ from the heme iron. Each acid is treated as an independent ionizable residue with a reference $\mathrm{p} K_{\mathrm{a}}$ of 4.9 (86). Ionized propionates favor oxidation, lowering the $E_{\mathrm{m}}$. Figure 5 shows $\Delta G_{\text {prop }}$ for protein equilibrated with reduced (Prot) and oxidized (Prot*) heme. $\Delta G_{\text {prop }}^{\text {Prot }}$ varies from $-40\left(b_{562}\right)$ to -170 (cyt f) $\mathrm{meV}$ (Table 2 and Figure $2 \mathrm{f}) . \Delta G_{\text {prop }}^{\text {Prot* }}$ is more negative $\left(-60\left(c_{553}\right)\right.$ to $\left.-270\left(c_{2}\right) \mathrm{meV}\right)$ since the propionates become more ionized or change conformation to stabilize the oxidized heme. The primary determinants of $\Delta G_{\text {prop }}$ are the solvent exposure and degree of ionization of the acids. The distance to the heme and heme exposure are important but vary little between cytochromes. The propionates are most solvent screened in $b_{5}$ 's and least in globins, so if fully ionized, the contribution of the propionates to the free energy of heme oxidation varies with $b_{5}<c^{\prime}<b_{562}<f<c$. Acid ionization at a given $\mathrm{pH}$ is controlled by the loss of reaction field energy, pairwise interactions with other residues, backbone dipoles, and between the propionates, the same electrostatic terms that determine heme oxidation at a given $E_{\mathrm{h}}$ (eq 1) (33). In MCCE, propionate ionization remains in equilibrium with heme oxidation.

In the $\beta$-structure cytochrome $f$, the propionates are fully ionized in both oxidation states despite being deeply buried because Arg 154 and 156 stabilize the charged acids and the propionic acids interact with each other weakly. In the globins the propionic acids are more deeply buried, have less stabilization from nearby bases, and interact more strongly with each other and so are only $\sim 50 \%$ ionized in the reduced and $\sim 70 \%$ ionized in the oxidized protein. Different structures of the same cytochrome $c$ have different ionization for the individual A or D ring acid, but the total ionization is fairly constant, not unexpected behavior for interacting acids (33). In the $\alpha \beta$ cytochrome $b_{5}$ the propionates are screened by solvent so are $\approx 90 \%$ ionized, with only small pairwise interaction with other groups or the heme. On heme oxidation they become fully ionized and change conformation making $\Delta G_{\text {prop }}$ more negative. In the four-helix bundle $b_{562}$, the propionic acids have a modest desolvation penalty but have little stabilization by other groups and so are only $\sim 40 \%$ ionized in the reduced protein. The oxidized heme shifts the $\mathrm{p} K_{\mathrm{a}}$ 's down so they are now $\sim 80 \%$ ionized.

$p H$ Dependence of the $E_{m}$. Cytochrome redox potential becomes $\mathrm{pH}$ dependent when acid and base $\mathrm{p} K_{\mathrm{a}}$ 's are shifted by heme oxidation (87). The residue contribution to the $\mathrm{pH}$ dependence is a function of the strength of its interaction with the heme and its ionization state in the reduced protein. In all cytochromes where the propionates are not fully ionized in the reduced state, heme oxidation is coupled to some proton loss (Figure 5). In contrast, in cytochrome $f$, despite their large $\Delta G_{\text {prop }}$, the acids are fully ionized in the reduced protein so cannot contribute to the $\mathrm{pH}$ dependence.

The propionate $\mathrm{p} K_{\mathrm{a}}$ 's were calculated by running MCCE at different pHs (33) (Supplementary Information IV). The calculated $b_{5} \mathrm{D}$ ring propionic acid $\mathrm{p} K_{\mathrm{a}}$ 's (5.4 oxidized and 6.0 reduced heme) are in good agreement with the experimentally measured $\mathrm{p} K_{\mathrm{a}}$ 's $(5.7$ oxidized and 5.9 reduced heme) (88). The $\mathrm{pH}$ dependence of the $b_{562} E_{\mathrm{m}}$ has been measured $(89,90)$ and calculated (Figure 6). The slope is about $-40 \mathrm{mV} / \mathrm{pH}$ near $\mathrm{pH} 7$, representing 0.7 protons released per electron. The residues that change ionization were identified (Figure 6b). At $\mathrm{pH} 7$ the propionates are most important as previously proposed (91). They have $\mathrm{p} K_{\mathrm{a}}$ 's of 6.0 and 7.4 in the reduced protein, which are shifted down by $\sim 1.0$ to $1.8 \mathrm{pH}$ units on heme oxidation (Supporting Information Table 4). His 63 is also involved (89). Glu 4 actually binds protons on heme oxidation as it responds to propionate ionization. While the slope of the $b_{562} E_{\mathrm{m}} / \mathrm{pH}$ plot matches the data fairly well, the calculated $E_{\mathrm{m}}$ is $\sim 80 \mathrm{mV}$ too high. This could be due to the propionate $\mathrm{p} K_{\mathrm{a}}$ 's being too high, which is unlikely since they match the experimental values (Supporting Information Table 4), or to the $E_{\mathrm{m}, \mathrm{sol}}$ used for the His-Met hemes being too positive.

$$
\Delta G_{\text {Prot } \rightarrow \text { Prot }}^{\text {red }} \text { and } \Delta G_{\text {Prot } \rightarrow \text { Prot* }}^{o x} \text { : Protein Reorganization in }
$$
$M C C E$. On oxidation, protein and surroundings reorganize to stabilize the new charge state. In MCCE relaxation is incorporated by the continuum response of the solvent water $(\epsilon=80)$ and the protein $(\epsilon=4)\left(\Delta \Delta G_{\mathrm{rxn}}\right)$ and by explicit changes in group ionization or position $\left(G_{\mathrm{Prot} \rightarrow \mathrm{Prot}^{*}}^{\mathrm{red}}\right.$ or $\Delta G_{\mathrm{Prot} \rightarrow \mathrm{Prot}^{*}}^{\mathrm{ox}}$ ) (Figure 3 and Table 2). $\Delta G_{\mathrm{Prot}^{\mathrm{r}} \rightarrow \mathrm{Prot}^{*}}^{\mathrm{red}}$ and $\Delta G_{\text {Prot } \rightarrow \text { Prot* }}^{\mathrm{ox}}$ include both the modification of direct pairwise interactions of residues with the heme given conformation or ionization changes $\left(\Delta \Delta G_{\text {prop }}, \Delta \Delta G_{\text {res }}\right)$ and the changes in intraprotein interactions due to these conformational changes. The result is that on oxidation the changes in direct pairwise interactions with the heme are more favorable than the total 


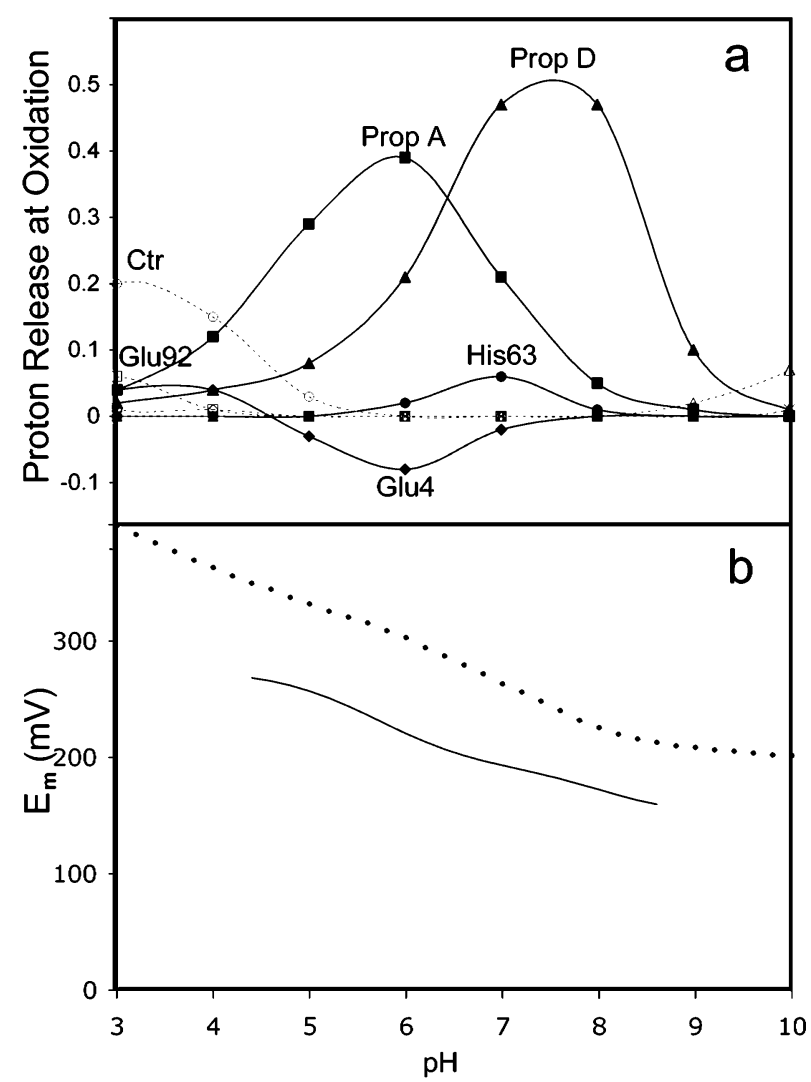

FIGURE 6: $\mathrm{pH}$ dependence of cytochrome $b_{562}$ from $E$. coli (256B, chain B). (a) Proton release vs $\mathrm{pH}$. Only residues which change ionization by more than $5 \%$ are shown. (b) Dotted line, the $\mathrm{pH}$ dependence of the $E_{\mathrm{m}}$ calculated by MCCE; solid line, the $\mathrm{pH}$ dependence derived from experimental $\mathrm{p} K_{\mathrm{a}}$ 's using $E_{\mathrm{m}}=E_{\mathrm{m}}{ }^{\mathrm{o}}+$ $59 \log \left[\left(1+10^{\mathrm{p} K_{1}^{\text {red }}-\mathrm{pH}}\right)\left(1+10^{\mathrm{p} K_{2}^{\text {red }}-\mathrm{pH}}\right)\right] /\left[\left(1+10^{\mathrm{p} K_{1}^{\mathrm{ox}}-\mathrm{pH}}\right)(1+\right.$ $\left.\left.10^{\mathrm{p} K_{2}{ }^{\mathrm{ox}}-\mathrm{pH}}\right)\right](104) \cdot \mathrm{p} K_{1}^{\text {red }}$ and $\mathrm{p} K_{2}^{\text {red }}$ are $\mathrm{p} K_{\mathrm{a}}$ 's of two ionizable groups with reduced heme and $\mathrm{p} K_{1}^{\mathrm{ox}}$ and $\mathrm{p} K_{2}^{\mathrm{ox}}$ values when the heme is oxidized. $\mathrm{p} K_{1}^{\mathrm{red}}=6.4, \mathrm{p} K_{1}^{\mathrm{ox}}=5.0, \mathrm{p} K_{2}^{\mathrm{red}}=8.4$, and $\mathrm{p} K_{2}^{\mathrm{ox}}$ $=7.7$ are from ref 89 .

energy change because of the cost of protein rearrangement. For example, in horse heart cytochrome $c, \Delta G_{\text {prop }}$ is -75 and $\Delta G_{\text {res }}-35 \mathrm{meV}$, more favorable in protein equilibrated with oxidized than reduced heme, while $\Delta G_{\text {Prot } \rightarrow \text { Prot* }}^{\mathrm{ox}}$ is only $-60 \mathrm{meV}$ (Table 2). Thus, about $50 \mathrm{meV}$ unfavorable residue-residue interactions are incurred when residueheme interactions are optimized (61)

While the largest protein response usually comes from changes in propionate ionization or conformation (Figure 5), other residues contribute. Cytochrome $c$ has a cluster, including Tyr 67, Asn 52, and in some structures a buried water, which reorient when the heme is oxidized. In horse heart $c$, the interaction of the oxidized heme with the cluster equilibrated in the reduced protein $\left(\Delta G_{\text {res }}^{\text {Prot }}\right)$ is small $(-7 \pm$ $22 \mathrm{meV}$ ), showing that this cluster is not preorganized to favor oxidation. However, the cluster $\Delta G_{\text {res }}^{\text {Prot }}$ is $-53 \pm 17$ $\mathrm{meV}$ after it rearranges when the heme is oxidized to stabilize the new change. The horse heart cytochrome structure 1HCR, which is crystallized with the heme oxidized, has an $E_{\mathrm{m}} 200$ $\mathrm{mV}$ lower than experiment (Supporting Information Table 2). Here the more stabilizing cluster configuration is already found in the reduced protein. No work is needed to reorganize the cluster which now over-stabilizes heme oxidation. Insufficient conformation sampling in MCCE that

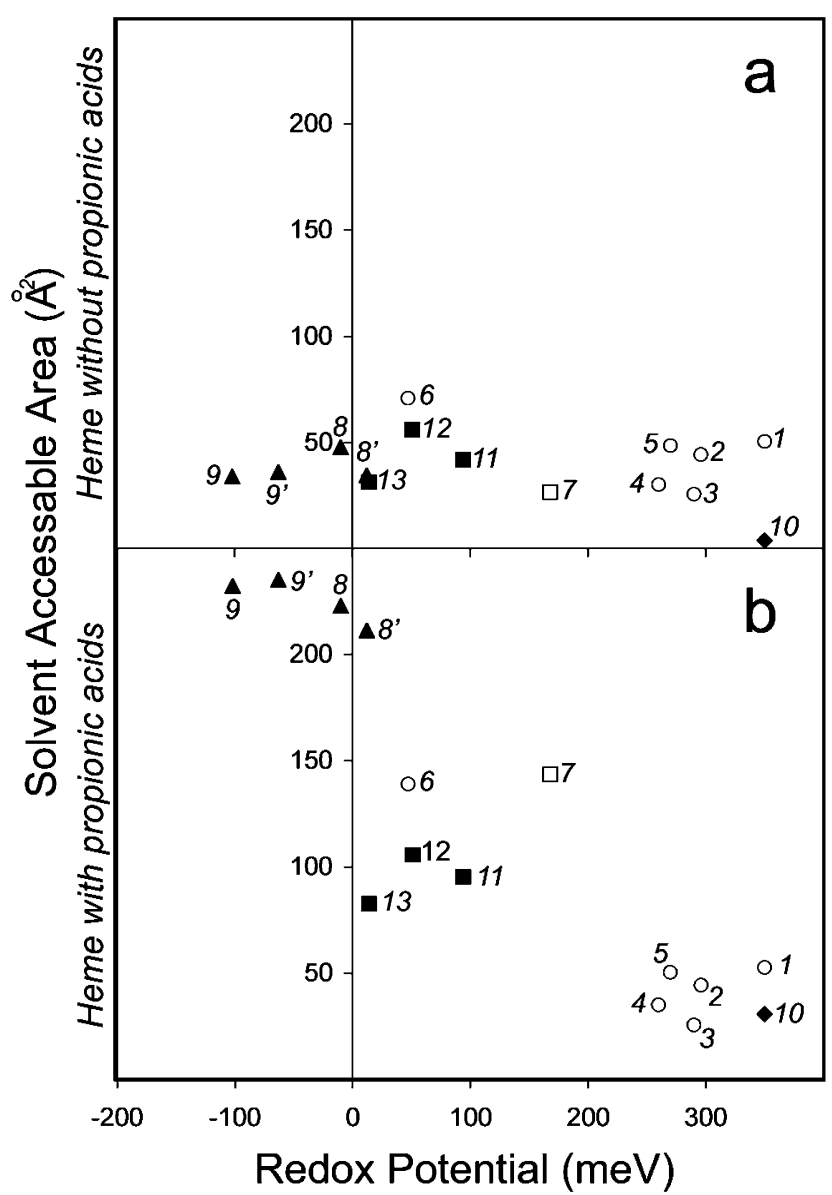

FIGURE 7: Heme exposure vs $\exp E_{\mathrm{m}}$ (a) without and (b) with the propionic acids. The surface probe radius is $1.4 \AA$. A fully exposed heme has a surface area of $650 \AA^{2}$, and the heme and propionates $850 \AA^{2}$.

keeps the backbone rigid does not allow this cluster to relax into the reduced protein conformation.

The energy for conformational change calculated here is related to, but different from, the Marcus reorganization energy $(\lambda)(7,24,25,35,92-95) . \Delta \Delta G_{\mathrm{rxn}}$ plus $\Delta G_{\mathrm{Prot} \rightarrow \text { Prot* }}^{\mathrm{red}}$ or $\Delta G_{\text {Prot } \rightarrow \text { Prot* }}^{\mathrm{ox}}$ contains the instantaneous electronic response $\left(\epsilon_{\text {optical }}=2\right)$ which is not included in $\lambda$. In addition, MCCE only accounts for a subset of the conformational changes so it will underestimates the total protein structural response.

Correlation between Heme Surface Exposure and $E_{m}$. Moving a heme from water to protein destabilizes the oxidized more than the reduced form by diminishing the favorable reaction field (solvation) energy, making the $E_{\mathrm{m}}$ more positive $(36,53,54)$. However, $\Delta \Delta G_{\text {Ixn }}$ varies by only $130 \mathrm{meV}$ in the 13 cytochromes studied and shows no correlation with $E_{\mathrm{m}}$ (Figure $2 \mathrm{~b}$ ). The hemes without propionates have only $6 \% \pm 2 \%$ of their surface exposed. This small variation in exposure does not correlate with $\Delta \Delta G_{\mathrm{rxn}}$ (Figure 7a). Rather, $\Delta \Delta G_{\text {rxn }}$ varies with the depth of heme burial. A weak correlation is found between $E_{\mathrm{m}}$ and the combined heme-propionate solvent exposure (Figure $7 \mathrm{~b}$ ). However, these acids are not conjugated into the heme ring, so their exposure does not directly change the heme charge distribution or reaction field energy. Rather, their pairwise electrostatic interactions with the heme, modulated by the structure, lower the $E_{\mathrm{m}}$. The $b_{5}$ 's have the lowest midpoints 
and exposed, ionized propionic acids. Cytochrome $f$, with the highest $E_{\mathrm{m}}$, has buried propionic acids which, stabilized by $2 \mathrm{Arg}$, are fully ionized. The buried propionates make the $E_{\mathrm{m}}$ more negative, and the Arg make it more positive. Cytochromes $c$ are at relatively positive potential with buried propionates that are only partially ionized. Last $c^{\prime} E_{\mathrm{m}}$ 's are only slightly more positive than the $b_{5}$ 's, while their propionic acids are significantly more buried. The interactions with the propionic acids are larger in $c^{\prime}$, but the backbone and ligand interactions destabilize oxidation more.

The V45I/V61I mutant of $b_{5}$ raises the $E_{\mathrm{m}}$, by $40 \mathrm{mV}$, which is reproduced here (Table 1), and has more buried propionates than the wild-type protein; MCCE includes no direct hydrophobic contribution of nonpolar residues such as Val or Ile to the $E_{\mathrm{m}}(85)$. While these residues can change the cytochrome surface, $\Delta \Delta G_{\mathrm{rxn}}$ is changed by less than 10 $\mathrm{mV}$ in the mutant. Burial could neutralize the propionates (96). However, MCCE shows that they have the same ionization as the wild-type protein (Figure 5) and even stronger interactions, with the oxidized heme shifting the $E_{\mathrm{m}}$ by an additional $-30 \mathrm{mV}$. Surprisingly, the positive $E_{\mathrm{m}}$ shift is due to the backbone near the His 39 ligand, which is twisted at Gly41 by the V45I mutation, raising $\Delta G_{\mathrm{pol}}$ and thus the $E_{\mathrm{m}}$ by $\sim 60 \mathrm{mV}$ (Table 2).

Variability of Calculated Values. The calculated values for $E_{\mathrm{m}}$ and the energy terms that contribute to $\Delta G_{\text {protein }}$ are averages of MCCE analysis of several structures of the same protein. The standard deviations show the variability. MCCE conformational sampling reduces differences due to initial side chain or water position, significantly reducing the dependence on the starting structure (33). However, the program provides only limited conformational flexibility and keeps the backbone fixed so the results remain dependent on the starting structure. For example, the cytochrome $c$ structures with oxidized hemes generally yield lower $E_{\mathrm{m}}$ 's $(1 \mathrm{HCR} 57 \mathrm{mV}$ ) than in reduced structures (2FRC $267 \mathrm{mV})$. Averaging the results from several structures increases the conformational space explored, reducing the error. The calculations become most uncertain when there are clusters of acids where strong interactions yield partial ionization. Here it is difficult to correctly assign which residues are charged (33). In the globins where the two propionic acids are partially protonated, there is significant variability in ionized acid assignment to the $\mathrm{A}$ and $\mathrm{D}$ ring in different structures. The problem is compounded in cytochrome $b_{562}$ that has a cluster, including Glu4, Glu8, and the propionic acids. Here the Glu in the A chain in structure 256B inhibits ionization of the propionates raising the $E_{\mathrm{m}}$.

\section{DISCUSSION}

The studies reported here show how cytochrome structure influences heme electrochemical midpoints in 13 cytochromes with 4 different folds (Figure 1) and $E_{\mathrm{m}}$ 's varying by $450 \mathrm{mV}$. MCCE was used to determine how each protein shifts the free energy of heme oxidation $\left(\Delta G_{\text {protein }}\right)$ using protein parameters from previous $\mathrm{p} K_{\mathrm{a}}$ calculations (33). Combining $\Delta G_{\text {protein }}$ with experimentally determined hemeligand reference redox potentials $\left(E_{\mathrm{m}, \mathrm{sol}}\right)$, yields calculated $E_{\mathrm{m}}$ 's in good agreement with experimental values (Figure 2a). Each protein uses different types of interactions to shift the heme $E_{\mathrm{m}}$ (Figure $2 \mathrm{~b}-\mathrm{f}$ ). Heme burial and resultant loss of reaction field energy $\left(\Delta \Delta G_{\mathrm{rxn}}\right)$, buried ionized or polar side chains $\left(\Delta G_{\text {res }}\right)$, propionic acid ionization and solvent screening $\left(\Delta G_{\text {prop }}\right)$, and backbone orientation near the ligands $\left(G_{\mathrm{pol}}\right)$ all play a role (Table 2$)$. However, the importance of each term is different in each structural class.

Globin $E_{\mathrm{m}}$ 's, while usually near $250 \mathrm{mV}$, range from 50 to $350 \mathrm{mV}$. They all have His-Met ligands with a relatively positive $E_{\mathrm{m}, \text { sol }}$, raising the $E_{\mathrm{m}}$ (Figure $2 \mathrm{c}$ ). Backbone amides in loops around the ligand residues point their HN's toward the heme raising the potential in the larger $c$ and $c_{2}$ 's, while a tighter $\beta$-turn loop in the smaller, low-potential $c_{553}$ does not (Figures $2 \mathrm{~d}$ and 4 ). Surface-ionizable residues change the redox potential little. A buried Arg usually shifts the $E_{\mathrm{m}}$ up (Supporting Information Table 4), while the partially ionized propionic acids shift the $E_{\mathrm{m}}$ down (Figure 2f). The globins show the largest conformational changes on heme oxidation, consistent with studies of cytochrome $c$ flexibility $(7,19,24,105)$. Shifts in propionic acid ionization (Figure 5) (106) and motions of a buried cluster of polar side chains contribute $(93,107)$.

Two classes of up and down four-helix bundles, $c^{\prime}$ and $b_{562}$, with $E_{\mathrm{m}}$ 's from 10 to $170 \mathrm{mV}$ were studied. $\Delta \Delta G_{\mathrm{rxn}}$ destabilizes heme oxidation less than in the globins because the hemes are closer to the surface. The helix amides around the ligands are parallel to the heme, so $\Delta G_{\mathrm{pol}}$ is less positive. While $b_{562}$ has His-Met ligands, the lower-potential $c$ 's have a single His ligand, lowering $E_{\mathrm{m}, \mathrm{sol}}$ by $\approx 100 \mathrm{mV}$. Each fourhelix bundle has two buried bases (usually Arg) that raise the $E_{\mathrm{m}}$. The four-helix bundles are rigid, changing little on heme oxidation. Random mutagenesis of 4 buried residues of $b_{562}$ yielded 28 mutants that generally lower the $E_{\mathrm{m}}(41$, 42). Thus, this wild-type protein is not optimized to stabilize the oxidized heme.

The $\alpha \beta$ roll is shaped like a cup with the heme at the top and the propionates pointing into solvent, with $E_{\mathrm{m}}$ 's from 10 to $-100 \mathrm{mV}$. The less deeply buried heme, with its smaller $\Delta \Delta G_{\mathrm{rxn}}$, stabilizes heme oxidation. In the small protein no individual side chain influences $\Delta G_{\text {res }}$ by as much as $30 \mathrm{meV}$. However, the summed contributions of all residues produce an unusual, negative $\Delta G_{\text {res. }}$ The backbone amides in loops that connect the ligands to the heme raise the potential at the heme. The $E_{\mathrm{m}}$ is also raised relative to other cytochromes by solvent exposure screening the propionates.

Cytochrome $f$, with the heme nestled at the edge of a $\beta$ sandwich, is the highest-potential cytochrome studied. The heme is deeply buried with a $\Delta \Delta G_{\mathrm{rxn}}$ similar to the globins. $\Delta G_{\mathrm{pol}}$ is very positive largely because the Ntr ligand sits at the end of an $\alpha$-helix. The oxidized heme has favorable interactions with the buried, fully ionized propionic acids, but this is offset by the two buried Arg that stabilize the anionic acids. Changes in side chain and propionate orientation occur to stabilize the oxidized heme.

Axial Ligands and the Reference Electrochemical Midpoint Potential. The axial ligands influence heme $E_{\mathrm{m}}$ 's primarily through bonding not electrostatic interactions. Therefore, the heme-ligand complex is treated as a single unit to be modified as a whole by the protein. Differences in ligandheme orientation or distance $(108,109)$ or groups that hydrogen bond to the ligand (110) were ignored, which may lead to errors (52). However, His ligands in proteins are found to lie in a narrow range of orientations, maximizing 
hydrogen bonding at the distal position and maintaining similar propionic acids positions (52). These constraints may keep $E_{\mathrm{m}, \mathrm{sol}}$ for each set of ligands relatively constant.

Reference $E_{\mathrm{m} \text {,sol }}$ can be obtained from microperoxidases with His-Met or bis-His axial ligands $(45,74-76,78)$ or from $E_{\mathrm{m}}$ changes resulting from ligand mutation (80-82). The good correspondence between calculation and experiment for the bis-His and His-Met cytochromes, 9 of the 13 studied here, show that MCCE provides a good value for $\Delta G_{\text {protein }} / n F$ (eq 3, Figure 2a). The $E_{\mathrm{m}, \text { sol }}$ of $-15 \mathrm{mV}$ for HisMet hemes used here is higher than the $-70 \mathrm{mV}$ found in microperoxidases but maintains the $E_{\mathrm{m}}$ difference found in mutations of Met to His ligands in cytochromes (80-82). The more positive $E_{\mathrm{m}, \mathrm{sol}}$ improves the match between calculation and experiment for the globins but may contribute to the too positive $E_{\mathrm{m}}$ for $b_{562}$ (Figure 6)

For the two ligand types with no available experimental values, the calculated $-\Delta G_{\text {protein }} / n F$ was subtracted from the measured $E_{\mathrm{m}}$ to predict $E_{\mathrm{m}, \text { sol }}$ (eq 3 ). This yields an $E_{\mathrm{m}, \mathrm{sol}}$ of $-111 \mathrm{mV}$ for the five-coordinate heme with 1 His ligand in cytochrome $c^{\prime}(111)$, intermediate between the solution values for His-Met and bis-His hemes. Thus, Met appears to be electron withdrawing, increasing the redox potential while His is electron donating. This is consistent with Met having a higher affinity for $\mathrm{Fe}(\mathrm{II})$ than $\mathrm{Fe}(\mathrm{III})$, while His has the opposite preference $(78,112)$.

An $E_{\mathrm{m}, \mathrm{sol}}$ of $-13 \mathrm{mV}$ is obtained for the His-Nter heme, close to that of the His-Met heme, suggesting that these ligands help give cytochrome $f$ a high potential. In contrast, substituting Lys for Met by mutation in $c_{550}$ lowers the $E_{\mathrm{m}}$ by as much as $-330 \mathrm{mV}\left(\mathrm{E}_{\mathrm{m}, \mathrm{sol}}-400 \mathrm{mV}\right)(80,113)$. For the His - Ntr $E_{\mathrm{m}, \mathrm{sol}}$ to be so positive, Ntr would need to be much more electron-withdrawing than a primary amine. A primary amine has a $\mathrm{p} K_{\mathrm{a}}$ of 10.8 , while it is 8.0 for Ntr. Thus $\Delta p K_{\mathrm{a}}$ shows Ntr binds its proton $10^{2.8}$ less tightly. A similar affinity shift, stabilizing binding $\mathrm{Fe}^{2+}$ over $\mathrm{Fe}^{3+}$, seen with other series of ligands $(112,114)$, could raise the Ntr $E_{\mathrm{m}, \mathrm{sol}}$ by $160 \mathrm{mV}$ relative to Lys. Thus, the derived predicted value for the His-Ntr heme is more positive than expected.

Loss of Reaction Field Energy, Heme Exposure, and Cytochrome $E_{m}$ 's. The heme solvent exposure has long been recognized as an important factor in the regulation of redox potentials. Early continuum electrostatics analysis $(53,115)$ considered if desolvation could be the dominant term in tuning heme electrochemistry. Recent publications also ascribe a strong correlation between solvent exposure and cytochrome $E_{\mathrm{m}}(78,101,116)$. However, there have been several electrostatic analyses, including this work, that evaluate $E_{\mathrm{m}}$ modulation by the protein with a more balanced treatment, showing that multiple factors tune $E_{\mathrm{m}}$ 's (Figure $2 \mathrm{~b}-\mathrm{f})(8,36,47,50,51,58)$. The electrochemistry of bisimidazole porphyrins attached to dendrites helps clarify the connection between the reaction field energy, porphyrin $E_{\mathrm{m}}$, and solvent exposure (117). $E_{\mathrm{m}}$ 's with simple peripheral groups, similar to microperoxidases, change from -25 to $100 \mathrm{mV}$ (vs SHE) as the solvent polarity is decreased from water, to $\mathrm{MeCN}(\epsilon \sim 40)$ to $\mathrm{CH}_{2} \mathrm{Cl}_{2}(\epsilon \sim 10)$. Thus, the $E_{\mathrm{m}}$ 's of exposed hemes are solvent dependent. Adding surface groups covering the heme (MW $\sim 12000$ ), raises the $E_{\mathrm{m}}$ to $\sim 370 \mathrm{mV}$, irrespective of the solvent. Thus, heme burial raises the $E_{\mathrm{m}}$, but buried hemes such as those found in cytochromes are influenced only a little by the solvent.
Pairwise Interactions with Protein Residues and Heme Propionates. Few residues modify cytochrome $E_{\mathrm{m}}$ 's significantly (Supporting Information, Table 4), consistent with the lack of correlation between $E_{\mathrm{m}}$ and cytochrome net charge. For example, Euglena cytochrome $c$ with a charge of -7 has an $E_{\mathrm{m}}$ of $370 \mathrm{mV}$, while the homologous c from Rhodopseudomonas gelatinosa with a +5 charge has an $E_{\mathrm{m}}$ of $28 \mathrm{mV}$ (5). Mutations of charged surface groups yield $E_{\mathrm{m}}$ changes of no more than $\approx 15 \mathrm{mV}(43,118,119)$ because solvent screening makes their electrostatic potential negligible at the heme. These surface charges are needed for binding the correct reaction partners (120).

Ionized and polar residues that are at least partially buried influence the heme $E_{\mathrm{m}}$. The propionic acids are always close to the heme, partially buried in the protein and so modify the $E_{\mathrm{m}}$ and its $\mathrm{pH}$ dependence (Figure 2e, 2f, 6 and 7). Although the propionates are always $\approx 8 \AA$ from the heme iron, differences in their ionization state and solvent exposure yield considerable variation in $\Delta G_{\text {prop. }}$. No acidic amino acids in the cytochromes studied here significantly modulate the heme $E_{\mathrm{m}}$ while some have been found in the large cytochrome subunit of $R$. viridis reaction centers (8). It may too hard in these small proteins to add negative charges near the propionic acids. All these cytochromes, except for the small, low-potential $c_{553}$ and $b_{5}$, have buried Arg which raise the $E_{\mathrm{m}}$ while stabilizing propionate ionization. The Argpropionate ion pair has much less influence than either charge alone. Mutations that remove buried Arg in cytochrome $b_{562}$ (42), $c$ (121), or cytochrome oxidase (122) lower the $E_{\mathrm{m}}$. There have been many studies where ionizable or polar residues are mutated in cytochromes $(17,118,123-127)$. Prior MCCE calculations on $E_{\mathrm{m}}$ changes in mutants are in reasonable agreement with experiment in reaction centers (128) and $b_{562}$ (129). Many studies have been made which modify nonpolar residues $(41,124,130,131)$. As found for the rat cytochrome $b_{5} \mathrm{~V} 45 \mathrm{I} / \mathrm{V} 61 \mathrm{I}$ mutant (96), nonpolar residues change $E_{\mathrm{m}}$ 's indirectly in MCCE. They help define the protein conformation, limit the position of polar residues, and keep water out of the protein core. However, as seen in the V45I/V61I mutant, changes in backbone geometry, site ionization, or burial of polar or charged groups can lead to unpredictable effects when hydrophobic residues are changed.

Redox Dependent Changes in Protein Structure. Comparison has been made of the structures of oxidized and reduced cytochromes $c(7,24,132-134), b_{5}(135,136), f$ $(137-139)$, and $b_{562}(140)$. MCCE can follow some changes in structure and ionization when the heme is oxidized. The rigid backbone is the most significant constraint on protein flexibility here. Changes in propionate ionization are the most important response to oxidation in many cytochromes (56, 141, 142). The reorientation of the propionates seen here is consistent with experimental findings for $b_{5}$ (136). Likewise the polar cluster in cytochrome $c(121)$ is shown to reorient to stabilize heme oxidation here modulating the $E_{\mathrm{m}}$.

\section{ACKNOWLEDGMENT}

We would like to thank Brian Gibney for helpful discussions about the electrochemistry of isolated heme-ligand complexes, Eduardo Torres for help at the beginning of the analysis of cytochrome electrochemistry, Yanjun Wang for maintaining the MCCE code, and David Rumschitzki for useful collaboration. 


\section{SUPPORTING INFORMATION AVAILABLE}

Tables of propionic acid rotamer library, energy terms for individual structures, ionization states of acidic and basic residues and residues that contribute significantly to the $\Delta G_{\text {res }}$, and calculated propionic acids $\mathrm{p} K_{\mathrm{a}}$ 's for $c_{551}, b_{562}$, and $b_{5}$. This material is available free of charge via the Internet at http://pubs.acs.org.

\section{REFERENCES}

1. Pettigrew, G. W., and Moore, G. R. (1987) Cytochromes c: Biological Aspects, Springer-Verlag, Berlin.

2. Moore, G. R., and Pettigrew, G. W. (1990) Cytochromes c: Evolutionary, Structural and Physiochemical Aspects, SpringerVerlag, Berlin.

3. Martin, A. C. R., Orengo, C. A., Hutchinson, E. G., Jones, S., Karmirantzou, M., Laskowski, R. A., Mitchell, J. B. O., Taroni, C., and Thornton, J. M. (1998) Structure 6, 875-884.

4. Lemberg, R., and Barrett, J. (1973) Cytochromes, Academic Press, London.

5. Cusanovich, M. A., Meyer, T. E., and Tollin, G. (1988) Heme Proteins 7, 37-91.

6. Moore, G. R. (1996) in Protein Electron Transfer (Bendall, D. S., Ed.) pp 189-216, Bios, Cambridge.

7. Churg, A. K., Weiss, R. M., Warshel, A., and Takano, T. (1983) J. Phys. Chem. 87, 1683-1694.

8. Gunner, M. R., and Honig, B. (1991) Proc. Natl. Acad. Sci. U.S.A. 88, 9151-9155.

9. Rabenstein, B., Ullmann, G. M., and Knapp, E. W. (1998) Biochemistry 57, 2488-2495.

10. Rabenstein, B., Ullmann, G. M., and Knapp, E. W. (2000) Biochemistry 39, 10487-96.

11. Alexov, E., and Gunner, M. (1999) Biochemistry 38, 8253-8270.

12. Stephens, P. J., Jollie, D. R., and Warshel, A. (1996) Chem. Rev. 96, 2491-2513.

13. Eidsness, M. K., Burden, A. E., Richie, K. A., Kurtz, D. M., Jr., Scott, R. A. S., E. T., Ichiye, T., Beard, B., Min, T., and Kang, C. (1999) Biochemistry 38, 14803-14809.

14. Ullmann, G. M., Noodleman, L., and Case, D. A. (2002) J. Biol. Inorg. Chem. 7, 632-639.

15. Noodleman, L., Lovell, T., Liu, T., Himo, F., and Torres, R. A. (2002) Cur. Opin. Struct. Biol. 6, 259-273.

16. Simonson, T. (2001) Curr. Opin. Struct. Biol. 11, 243-252.

17. Cutler, R. L., Davies, A. M., Creighton, S., Warshel, A., Moore, G. R., Smith, M., and Mauk, A. G. (1989) Biochemistry 28, $3188-$ 3197.

18. Sham, Y. Y., Chu, Z. T., Tao, H., and Warshel, A. (2000) Proteins 39, 393-407.

19. Simonson, T. (1998) J. Am. Chem. Soc. 120, 4873-4878.

20. Soares, C. M., Martel, P. J., Mendes, J., and Carrondo, M. A. (1998) Biophys. J. 74, 1708-1721.

21. Olsson, M. H., Hong, G., and Warshel, A. (2003) J. Am. Chem. Soc. $125,5025-5039$.

22. Friesner, R. A., and Dunietz, B. D. (2001) Acc. Chem. Res 34, $351-358$.

23. Gunner, M. R., Saleh, M., Cross, E., ud-Doula, A., and Wise, M. (2000) Biophys. J. 78, 1126-1144.

24. Muegge, I., Qi, P. X., Wand, A. J. W., Chu, Z. T., and Warshel, A. (1997) J. Phys. Chem. 101, 825-836.

25. Simonson, T. (2002) Proc. Natl. Acad. Sci. U.S.A. 99, 65446549.

26. Warshel, A. (1981) Biochemistry 20, 3167

27. Bashford, D., and Karplus, M. (1991) J. Phys. Chem. 95, 95569561.

28. Yang, A.-S., Gunner, M. R., Sampogna, R., Sharp, K., and Honig, B. (1993) Proteins 15, 252-265.

29. Antosiewicz, J., McCammon, J. A., and Gilson, M. K. (1996) Biochemistry 35, 7819-7833.

30. Alexov, E. G., and Gunner, M. R. (1997) Biophys. J. 72, 20752093.

31. Mehler, E. L., and Guarnieri, F. (1999) Biophys. J. 77, 3-22.

32. Schutz, C. N., and Warshel, A. (2001) Proteins 44, 400-417.

33. Georgescu, R. E., Alexov, E. G., and Gunner, M. R. (2002) Biophys J. 83, 1731-1748.

34. Warshel, A., and Russell, S. T. (1984) Q. Rev. Biophys. 17, 283422.
35. Warshel, A., and Churg, A. K. (1983) J. Mol. Biol 168, 687694.

36. Churg, A. K., and Warshel, A. (1986) Biochemistry 25, 16751681.

37. Warwicker, J. (1986) J. Theor. Biol 121, 199-210.

38. Honig, B., and Nicholls, A. (1995) Science 268, 1144-1149.

39. Warshel, A., and Papazyan, A. (1998) Curr. Opin. Struct. Biol. 8 , $211-217$.

40. Mauk, A. G., and Moore, G. R. (1997) J. Biol. Inorg. Chem. 2, $119-125$.

41. Springs, S. L., Bass, S. E., McLendon, G. L. (2000) Biochemistry $39,6075-6082$.

42. Springs, S. L., Bass, S. E., Bowman, G., Nodelman, I., Schutt, C. E., and McLendon, G. L. (2002) Biochemistry 41, 4321-4328.

43. Bertini, I., Gori-Savellini, G., and Luchinat, C. (1997) J. Biol. Inorg. Chem. 2, 109-113.

44. Battistuzzi, G., Borsari, M., and Sola, M. (2001) Antioxid. Redox Signal 3, 279-91.

45. Battistuzzi, G., Borsari, M., Cowan, J. A., Ranieri, A., and Sola, M. (2002) J. Am. Chem. Soc. 124, 5315-5324.

46. Zhou, H. X. (1997) J. Biol. Inorg. Chem. 2, 109-113.

47. Gunner, M. R., Alexov, E., Torres, E., and Lipovaca, S. (1997) J. Biol. Inorg. Chem. 2, 126-134.

48. Warshel, A., Papazyan, A., and Muegge, I. (1997) J. Biol. Inorg. Chem. 2, 143-152.

49. Baptista, A. M., Martel, P. J., and Peterson, S. B. (1997) Proteins: Struct., Funct., Genet. 27, 523-544.

50. Baptista, A., Martel, P. J., and Soares, C. M. (1999) Biophys. J. 76, 2978-2998.

51. Martel, P. J., Soares, C. M., Baptista, A. M., Fuxreiter, M., NaraySzabo, G., Louro, R. O., and Carrondo, M. A. (1999) J. Biol. Inorg. Chem. 4, 73-86.

52. Zaric, S. D., Popovic, D. M., and Knapp, E. W. (2001) Biochemistry 40, 7914-7928.

53. Kassner, R. J. (1972) Proc. Natl. Acad. Sci. U.S.A. 69, $2263-$ 2267.

54. Kassner, R. J. (1973) J. Am. Chem. Soc. 95, 2674-2676.

55. Warwicker, J., and Watson, H. C. (1982) J. Mol. Biol. 157, 671679 .

56. Rogers, N. K., Moore, G. R., and Sternberg, M. J. (1985) J. Mol. Biol. 182, 613-616.

57. Rogers, N. K., and Moore, G. R. (1988) Febs Lett. 228, 69-73. 58. Ullmann, G. M. (2000) J. Phys. Chem. B 104, 6923-6301.

59. Teixeira, V. H., Soares, C. M., and Baptista, A. M. (2002) J. Biol. Inorg. Chem. 7, 200-216.

60. Rau, H. K., DeJonge, N., and Haehnel, W. (1998) Proc. Natl Acad. Sci. U.S.A. 95, 11526-11531.

61. Gunner, M. R., and Alexov, E. (2000) Biochim. Biophys. Acta $1458,63-87$

62. Antosiewicz, J., McCammon, J. A., and Gilson, M. K. (1994) J. Mol. Biol. 238, 415-436.

63. You, T. J., and Bashford, D. (1995) Biophys. J. 69, 1721-1733.

64. Beroza, P., and Case, D. (1996) J. Phys. Chem. 100, 20156-20163.

65. Nielsen, J. E., Anderson, K. V., Honig, B., Hooft, R. W. W., Klebe, G., Vriend, G., and Wade, R. C. (1999) Prot. Eng. 12, 657-662.

66. Sham, Y. Y., Muegge, I., and Warshel, A. (1998) Biophys. J. 74 1744-1753.

67. Sham, Y. Y., Chu, Z. T., and Warshel, A. (1997) J. Phys. Chem. B 101, 4458-4472.

68. Sridharan, S., Nicholls, A., and Honig, B. (1992) Biophys. J. 61 , A174.

69. Bharadwaj, R., Windemuth, A., Sridharan, S., Honig, B., and Nicholls, A. (1995) J. Comput. Chem. 16, 898-913.

70. Gu, Z., Ridenoor, C. F., Bronnimann, C. E., Iwashita, T., and McDermott, A. (1996) J. Am. Chem. Soc. 118, 822-829.

71. Nicholls, A., and Honig, B. (1991) J. Comput. Chem. 12, 435445.

72. Sitkoff, D., Sharp, K. A., and Honig, B. (1994) J. Phys. Chem. 98, 1978-1988.

73. Kashiwagi, H., and Obara, S. (1981) Int. J. Quantum Chem. 20, 843-59.

74. Harbury, H. A., and Loach, P. A. (1960) J. Biol. Chem. 255, 36403645.

75. Harbury, H. A., and Loach, P. A. (1960) J. Biol. Chem. 235, 36463653.

76. Wilson, G. S. (1974) Bioelectrochem. Bioenerg. 1, 172-179.

77. Adams, P. A., Baldwin, D. A., and Marques, H. M. (1996) in Cytochrome c (Scott, R. A., and Mauk, A. G., Eds.) pp 635692, University Science Books, Sausalito, CA. 
78. Tezcan, F. A., Winkler, J. R., and Gray, H. B. (1998) J. Am. Chem. Soc. $120,13383-13388$.

79. Harbury, H. A., Cronin, J. R., Fanger, M. W., Hettinger, T. P., Murphy, A. J., Meyer, Y. P., and Vinogradov, S. N. (1965) Proc. Natl. Acad. Sci. U.S.A. 54, 1658-1664.

80. Wallace, C. J. A., and Clark-Lewis, I. (1992) J. Biol. Chem. 1992 , $3852-3861$.

81. Raphael, A. L., and Gray, H. B. (1989) Proteins 6, 338-340.

82. Miller, G. T., Zhang, B., Hardman, J. K., and Timkovich, R. (2000) Biochemistry 39, 9010-9017.

83. Wu, J., Gan, J. H., Xia, Z. X., Wang, Y. H., Wang, W. H., Xue, L. L., Xie, Y., and Huang, Z. X. (2000) Proteins 40, 249-57.

84. Durley, R. C. E., and Mathews, F. S. (1996) Acta Crystallogr., Sect. D: Biol. Crystallogr. 52, 65.

85. Xue, L., Wang, Y., Xie, Y., Yao, P., Wang, W., Qian, W., and Huang, Z. (1999) Biochemistry 38, 11961-11972.

86. Lide, D. R. (1990) CRC Handbook of Chemistry and Physics, CRC Press, Boca Raton, FL.

87. Cramer, W. A., and Knaff, D. B. (1991) Energy Transduction in Biological Membranes: A Textbook of Bioenergetics, SpringerVerlag, New York.

88. Das, D. K., and Medhi, O. K. (1998) J. Inorg. Biochem. 70, 8390

89. Barker, P. D., Butler, J., Oliveira, P., Hill, H. A., and Hunt, N. I. (1996) Inorg. Chim. Acta 252, 71-77.

90. Moore, G. R., Williams, R. J. P., Peterson, J., Thomson, A. J., and Mathews, S. (1985) Biochim. Biophys. Acta 829, 83-96.

91. Moore, G. R., Pettigrew, G. W., Pitt, R. C., and Williams, R. J. P. (1980) Biochim. Biophys. Acta 590, 261-271.

92. Marcus, R. A., and Sutin, N. (1985) Biochim. Biophys. Acta 811, $265-322$.

93. Langen, R., Brayer, G. D., Berghuis, A. M., McLendon, G., Sherman, F., and Warshel, A. (1992) J. Mol. Biol. 224, 589600 .

94. Sharp, A. S. (1998) Biophys. J. 73, 1241-1250.

95. Parson, W. W., Chu, Z. T., and Warshel, A. (1998) Biophys. J. $74,182-91$

96. Wirtz, M., Oganesyan, V., Zhang, X., Studer, J., and Rivera, M. (2000) Faraday Discuss. 116, 221-34.

97. Meyer, T. E., Watkins, J. A., Przysiecki, C. T., Tollin, G., and Cusanovich, M. A. (1984) Biochemistry 23, 4761-4767.

98. Meyer, T. E., and Kamen, M. D. (1982) Adv. Prot. Chem. 35, $105-212$.

99. Northup, S. H. (1996) in Protein Electron Transfer (Bendall, D. S., Ed.) pp 69-98, Bios, Cambridge.

100. Benini, S., Borsari, M., Ciurli, S., Dikiy, A., and Lamborghinin, M. (1998) J. Biol. Inorg. Chem. 3, 371-382.

101. Rivera, M., Seetharaman, R., Girdhar, D., Wirtz, M., Zhang, X., Wang, X., and White, S. (1998) Biochemistry 37, 1485-1494.

102. Meyer, T. E., Cheddar, G., Bartsch, R. G., Getzoff, E. D., Cusanovich, M. A., and Tollin, G. (1986) Biochemistry 25, $1383-$ 1390.

103. Yamaanka, T. (1992) Group c Cytochromes, Japan Scientific Societies Press, Tokoyo.

104. Maroti, P., and Wraight, C. A. (1988) Biochim. Biophys. Acta 934, 329-347.

105. Garcia, A. E., and Hummer, G. (1999) Proteins 36, 175-191.

106. Schlereth, D. D., and Mantele, W. (1993) Biochemistry 32, 1118 1126.

107. Berghuis, A. M., Guillemette, J. G., McLendon, G., Sherman, F., Smith, M., and Brayer, G. D. (1994) J. Mol. Biol. 236, 786-799.

108. Safo, M. K., Nesset, M. J. M., Walker, F. A., Debrunner, P. G., and Scheidt, W. R. (1997) J. Am. Chem. Soc. 117, 9438-9448.

109. Sarma, S., Dangi, B., Yan, C., DiGate, R. J., Banville, D. L., and Guiles, R. D. (1997) Biochemistry 36, 5645-5657.

110. Obrien, P., and Sweigart, D. A. (1985) Inorg. Chem. 24, 14051409.

111. Kassner, R. J. (1991) Biochim. Biophys. Acta 1058, 8-12.
112. Nesset, M. J. M., Shokhirev, N. V., Enemark, P. D., Jacobson, S. E., and Walker, F. A. (1996) Inorg. Chem. 35, 5188-5200.

113. Ubbink, M., Campos, A. P., Teixeira, M., Hunt, N. I., Hill, H. A. O., and Canters, G. W. (1994) Biochemistry 33, 10051-10059.

114. Kadish, K. M., and Bottomley, L. A. (1980) J. Inorg. Chem. 19, $832-836$

115. Stellwagen, E. (1978) Nature 275, 73-74

116. Fantuzzi, A., Sadeghi, S., Valentti, F., Rossi, G. L., and Gilardi, G. (2002) Biochemistry 41, 8718-8724.

117. Weyermann, P., and Diederich, F. (2002) Helv. Chima. Acta 85 , $571-597$.

118. Smith, H. T., Staudenmayer, N., and Millett, F. (1977) Biochemistry 16, 4977-4974.

119. Rees, D. C. (1980) J. Mol. Biol. 141, 323-326.

120. Tiede, D. M., Vashishta, A.-C., and Gunner, M. R. (1993) Biochemistry 32, 4515-4531.

121. Lo, T. P., Komar-Panicucci, S. Sherman, F., McLendon, G., and Brayer, G. D. (1995) Biochemistry 34, 5259-5268.

122. Kannt, A., Pfitzner, U., Ruitenberg, M., Hellwig, P., Ludwig, B., Mantele, W., Fendler, K., and Michel, H. (1999) J. Biol. Chem. 274, 37974-81.

123. Langen, R., Braver, G. D., Berghuis, A. M., McLendon, G., Sherman, F., and Warshel, A. (1992) J. mol. Biol. 224, 589600.

124. Saraiva, L. M., Salgueiro, C. A., da Costa, P. N., Messias, A. C., LeGall, J., van Dongen, W. M., and Xavier, A. V. (1998) Biochemistry 37, 12160-5.

125. Wang, Z. Q., Wang, Y. H., Wang, W. H., Xue, L. L., Wu, X. Z., Xie, Y., and Huang, Z. X. (2000) Biophys Chem 83, 3-17.

126. Cesareni, G., Spiedel, D., Jones, M. R., and Robert, B. (2002) FEBS Lett. 527, 171-175.

127. Schlarb-Ridley, B. G., Bendall, D. S., and Howe, C. J. (2002) Biochemistry 41, 3279-85.

128. Alexov, E., Miksovska, J., Baciou, L., Schiffer, M., Hanson, D., Sebban, P., and Gunner, M. R. (2000) Biochemistry 39, 59405952.

129. Springs, S. L., Mao, J., Hauser, K., Gunner, M. R., and McLendon, G. Proc. Natl. Acad. Sci. U.S.A., submitted.

130. Sarma, S., DiGate, R. J., Goodin, D. B., Miller, C. J., and Guiles, R. D. (1997) Biochemistry 36, 5658-5668.

131. Gong, X. S., Wen, J. Q., and Gray, J. C. (2000) Eur. J. Biochem. $267,1732-42$

132. Zhao, D., Hutton, H. M., Gooley, P. R., MacKenzie, N. E., and Cusanovich, M. A. (2000) Protein Sci. 9, 1828-37.

133. Harrenga, A., Reincke, B., Ruterians, H., Ludwig, B., and Michel, H. (2000) J. Mol. Biol. 295, 667-78.

134. Iverson, T. M., Arciero, D. M., Hooper, A. B., and Rees, D. C. (2001) J. Biol. Inorg. Chem. 6, 390-7.

135. Banci, L., Bertini, I., Ferroni, F., and Rosato, A. (1997) Eur. J. Biochem. 249, 270-9.

136. Arnesano, F., Banci, L., Bertini, I., Felli, I. C. (1998) Biochemistry 37, $173-184$

137. Martinez, S. E., Huang, D., Ponomarev, M., Cramer, W. A., and Smith, J. L. (1996) Protein Sci. 5, 1081-1092.

138. Ponamarev, M. V., and Cramer, W. A. (1998) Biochemistry 37, 17199-208.

139. Sainz, G., Carrell, C. J., Ponamarev, M. V., Soriano, G. M., Cramer, W. A., and Smith, J. L. (2000) Biochemistry 39, 91649175.

140. Arnesano, F., Banci, L., Bertini, I., Faraone-Mennella, J., Rosato, A., Barker, P. D., and Fersht, A. R. (1999) Biochemistry 38, 865770.

141. Behr, J., Hellwig, P., Mantele, W., and Michel, H. (1998) Biochemistry 37, 7400-7406.

142. Cai, M., and Timkovich, R. (1992) FEBS Lett. 311, 213-6.

BI027288K 